\title{
Toward Improving Ice Water Content and Snow-Rate Retrievals from Radars. Part II: Results from Three Wavelength Radar-Collocated In Situ Measurements and CloudSat-GPM-TRMM Radar Data
}

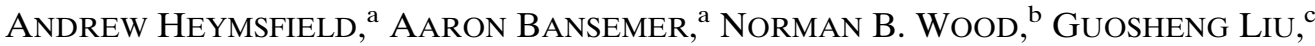 \\ Simone Tanelli, ${ }^{\mathrm{d}}$ Ousmane O. Sy, ${ }^{\mathrm{d}}$ Michael Poellot, ${ }^{\mathrm{e}}$ and Chuntao Liu ${ }^{\mathrm{f}}$

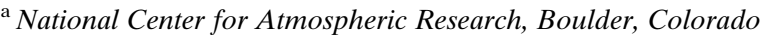 \\ ${ }^{\mathrm{b}}$ University of Wisconsin-Madison, Madison, Wisconsin \\ ${ }^{\mathrm{c}}$ Florida State University, Tallahassee, Florida \\ ${ }^{\mathrm{d}}$ Jet Propulsion Laboratory, California Institute of Technology, Pasadena, California \\ ${ }^{\mathrm{e}}$ University of North Dakota, Grand Forks, North Dakota \\ ${ }^{\mathrm{f}}$ Texas A\&M, Corpus Christi, Texas
}

(Manuscript received 14 June 2017, in final form 16 October 2017)

\begin{abstract}
Two methods for deriving relationships between the equivalent radar reflectivity factor $Z_{e}$ and the snowfall rate $S$ at three radar wavelengths are described. The first method uses collocations of in situ aircraft (microphysical observations) and overflying aircraft (radar observations) from two field programs to develop $Z_{e}-S$ relationships. In the second method, measurements of $Z_{e}$ at the top of the melting layer (ML), from radars on the Tropical Rainfall Measuring Mission (TRMM), Global Precipitation Measurement (GPM), and CloudSat satellites, are related to the retrieved rainfall rate $R$ at the base of the ML, assuming that the mass flux through the ML is constant. Retrievals of $R$ are likely to be more reliable than $S$ because far fewer assumptions are involved in the retrieval and because supporting ground-based validation data are available. The $Z_{e}-S$ relationships developed here for the collocations and the mass-flux technique are compared with those derived from level 2 retrievals from the standard satellite products and with a number of relationships developed and reported by others. It is shown that there are substantial differences among them. The relationships developed here promise improvements in snowfall-rate retrievals from satellite-based radar measurements.
\end{abstract}

\section{Introduction}

Accurate quantification of the amount, vertical distribution, and phase (liquid or ice) of precipitation is critical for hydrological applications and for understanding the current state of Earth's climate and its future changes (Stephens et al. 2002; Trenberth et al. 2007). Ground-based measurements of precipitation are commonly considered to be the most accurate, but they are located almost exclusively over populated land and thus not available in many regions of the world. The deployment of satelliteborne active remote sensors over the past two decades has resulted in multiple sources of cloud and precipitation datasets covering large portions of Earth. However, the quantification and understanding of uncertainties associated with remotely sensed satellite data remain a challenging research topic (AghaKouchak et al. 2012). The

Corresponding author: Andrew Heymsfield, heyms1@ucar.edu uncertainties of satellite precipitation data arise from different factors, including the sensor itself, retrieval error, and spatial and temporal sampling, among others (Hong 2007). The motivation for this study is to improve active satellite-based retrievals of precipitation and precipitating condensate aloft, emphasizing the ice phase.

Satellite-based radars, including those on CloudSat, the Global Precipitation Measurement (GPM), and in the future Earth Cloud Aerosol and Radiation Explorer (EarthCARE), have the potential to provide the data needed to quantify the global distribution of snow precipitation rate $S$. To first order, relationships can be developed between the equivalent radar reflectivity $Z_{e}$ measured by these radars and $S$. In some cases, it has been

Publisher's Note: This article was revised on 28 February 2018 to correct the expansion of TRMM in the abstract and to fix two instances of a spelling that did not adhere to American Meteorological Society style when originally published. 
possible to measure radar reflectivities with a groundbased radar at the same time that snowfall rates were measured at the surface (Puhakka 1975; Boucher and Wieler 1985; Fujiyoshi et al. 1990; Wolfe and Snider 2012). It is not possible to compare the instantaneous snowfall rates retrieved from radar measurements to those from a ground-based instrument because of the large differences in their sample volumes, thus long averaging times (from $5 \mathrm{~min}$ to $1 \mathrm{~h}$ ) are needed. This increases the scatter in the $Z_{e}-S$ relationship.

Difficulties inherent in not only measuring the snowfall rate at the ground but also collocating snowfall-rate measurements with radar measurements have led to the development of approaches whereby ground-based and radar measurements are not needed. Rather, $Z_{e}-S$ relationships are developed using measurements of particle size distributions (PSD) and observed or assumed ice particle shapes (e.g., Sekhon and Srivastava 1970). Shape information is necessary not only because the backscatter cross section is approximately proportional to the square of the ice particle mass but also because, as the radar wavelength decreases, non-Rayleigh scattering effects become increasingly more important. Non-Rayleigh scattering and particle shape strongly affect the shapedependent backscatter cross sections $(\sigma)$ from the ice hydrometeors. Because non-Rayleigh scattering becomes significant when large ice particles are measured with $\mathrm{Ku}$ - through $\mathrm{W}$-band radars, considerable attention has been given to methods to determine the $\sigma$ of the ice particles (e.g., Matrosov 2007, hereafter M07; Liu 2004, 2008a; Matrosov et al. 2009; Kulie and Bennartz 2009; Hiley et al. 2011). Calculating $\sigma$ is especially challenging at $\mathrm{W}$ band, the frequency of CloudSat (Hong 2007; M07; Liu 2008b; Kulie and Bennartz 2009; Kulie et al. 2010; Wood et al. 2015).

The satellite-based retrieval algorithms also make assumptions about the PSD, the ice density $\left(\rho_{b}\right)$, the ice particle terminal velocities $\left(V_{t}\right)$, and $\sigma$. The CloudSat Snow Profile product (2C-SNOW-PROFILE) provides estimates of vertical profiles of snowfall rate along with snow size distribution parameters and snow water content for radar reflectivity profiles observed by the CloudSat Cloud Profiling Radar (CPR). The retrieval algorithms for GPM and Tropical Rainfall Measuring Mission (TRMM) are similar to each other. The PSD are derived from specific gamma-type PSD models, separated into stratiform and convective regions (Iguchi et al. 2010). Relationships are then developed between $Z_{e}$ and the median volume diameter of the PSD (Iguchi et al. 2010). Once $Z_{e}$ is obtained, then the functional form of the size distribution can be specified and the rainfall rate $R$ (Iguchi et al. 2000) (or $S$ ) can be derived. Ice density is taken to be $0.1 \mathrm{~g} \mathrm{~m}^{-3}$, terminal velocity is based on the ice density, and $V_{t}$ is corrected for atmospheric pressure $(P)$. The GPM combined algorithm, correcting for non-Rayleigh backscatter cross sections (Grecu et al. 2016), uses the ice particle models of Kuo et al. (2016).

The radar reflectivity is a function of the ice particle size distribution, ice particle shapes and masses, and the radar wavelength, whereas the snow precipitation rate depends on the size distribution, masses, and terminal velocities. Furthermore, field program datasets are restricted to limited geographical areas and cloud conditions. Owing to the many assumptions often needed to derive both $Z_{e}$ and $S$, even when in situ measurements of the radar reflectivity and size distributions are available, it can be problematic to develop reliable $Z_{e}-S$ relationships.

The specific goal of this study, therefore, is to develop relationships between the equivalent radar reflectivity factor and snowfall rate applicable to $\mathrm{W}, \mathrm{Ka}$, and $\mathrm{Ku}$ bands. The two methods employed here to develop $Z_{e}-S$ relationships for multiple wavelengths are described in section 2 together with the regional and global datasets used. The results are presented in section 3. Section 4 discusses the findings, and the conclusions are summarized in section 5 .

\section{Methodology}

\section{a. Aircraft-based snowfall-rate estimates and radar measurements}

The most direct method [observations (OBS)] to develop snowfall-rate-radar reflectivity relationships at multiple wavelengths is to use PSD measurements from in-cloud aircraft probes to estimate $S$, and then to relate these to radar measurements at $\mathrm{Ku}, \mathrm{Ka}$, and $\mathrm{W}$ bands from an above-cloud research aircraft when the in-cloud and overflying aircraft were nearly collocated spatially and temporally. With this method, we use data from the GPM Cold Season Precipitation Experiment (GCPEX) in 2012 and the 2015 Olympic Mountain Experiment (OLYMPEX) field programs.

The primary collocation dataset is from the OLYMPEX field campaign conducted in the vicinity of the Olympic Peninsula in Washington State. During OLYMPEX, the University of North Dakota (UND) Cessna Citation flew 20 missions, spanning the in-cloud temperature range from $-32^{\circ}$ to $9^{\circ} \mathrm{C}$. On board the $\mathrm{Ci}$ tation, the microphysical datasets-PSD and particle shape (habit) information-were acquired from three instruments. These instruments, the two-dimensional stereo probe (2D-S; Lawson et al. 2006) and two orthogonally mounted High Volume Precipitation Spectrometers (HVPS-3), collected cloud particle size distribution and cloud particle imagery data over the size range from about $50 \mu \mathrm{m}$ to $>2 \mathrm{~cm}$. The HVPS-3, which was mounted such that it looked up and down at 
particles passing through its sample volume, was used in this analysis. For a description of the use of the HVPS-3 probe in this orientation on the Citation aircraft, see Heymsfield et al. (2015) and Giangrande et al. (2016). The PSDs were used to derive bulk cloud properties, including the ice water content (IWC); $R$, with terminal velocities $V_{t}$ derived using the formulation of Szyrmer and Zawadzki (1999); and $S$, with $V_{z}$ derived from Heymsfield and Westbrook (2010) at the measurement pressure level and also at $1000 \mathrm{hPa}$. The massdimensional relationship used for the calculations was $m=0.0061 D^{2.05}$ (Heymsfield et al. 2013). From the numerous in situ datasets where direct measurements of the IWC were measured, we estimate that the uncertainty in our IWC estimate is $\pm 20 \%$ (Heymsfield et al. 2013). Given that the cross-sectional area of the ice particles in their fall orientation were directly measured by the particle probes, the calculation of their terminal velocity based on Heymsfield and Westbrook (2010) is also likely to be of order $\pm 10 \%$. A reasonable estimate of the snowfall rate-the integration of the particle mass and terminal velocity across the size distribution-is therefore about $\pm 30 \%$.

The in situ dataset was complemented by overflights from the NASA DC-8 aircraft, containing the ThirdGeneration Airborne Precipitation Radar (APR-3), a triple-frequency $(\mathrm{Ku}, \mathrm{Ka}$, and $\mathrm{W}$ bands, 13,35 , and $94 \mathrm{GHz}$, respectively) Doppler, dual-polarization radar system, downward pointing. It is similar to the APR-2 radar (Sadowy et al. 2003; Braun et al. 2013), with the addition of $\mathrm{W}$ band.

During OLYMPEX, coordinated flights were made in precipitating clouds associated with weather systems during the period from 12 November to 20 December 2015. To designate times when the two aircraft were collocated, we required the Citation and DC-8 aircraft to be $<2 \mathrm{~km}$ in horizontal separation at a given time. There were more than 13000,1 -s collocations at temperatures $(T)$ below $0^{\circ} \mathrm{C}$. The mean horizontal displacement of the two aircraft was $0.75 \pm 0.55 \mathrm{~km}$ and the median displacement was $0.6 \mathrm{~km}$. The maximum time difference was $300 \mathrm{~s}$, the mean $-9 \pm 170 \mathrm{~s}$, and the median was $-10 \mathrm{~s}$. Sampling at temperatures above $0^{\circ} \mathrm{C}$ provided a check on the estimates of $Z_{e}$ when assumptions about the mass-diameter relationships were not necessary. For temperatures above $3^{\circ} \mathrm{C}$-selected here to remove instances in the melting layer where ambiguity in the particle phase might occur-there were 4800 collocations. About the same number of 1-s collocations were obtained for temperatures above $0^{\circ} \mathrm{C}$, from $0^{\circ}$ to $-10^{\circ} \mathrm{C}$ and from $-10^{\circ}$ to $-20^{\circ} \mathrm{C}$, but about one-third as many were obtained at temperatures below $-20^{\circ} \mathrm{C}$.
The second dataset, GCPEX, was collected over and near the Ontario, Canada, Environment Canada Centre for Atmospheric Research Experiments (CARE) site in January-February 2012. During GCPEX (SkofronickJackson et al. 2015), the UND Citation aircraft flew 13 missions, collecting in situ microphysical data with cloud imaging probes (2D-C, CIP) and an HVPS-3 probe, covering the size range from about $100 \mu \mathrm{m}$ to $>2 \mathrm{~cm}$. The NASA DC-8 aircraft contained the Second-Generation Airborne Precipitation Radar (APR-2), comprising dualfrequency $\mathrm{Ku}$ and $\mathrm{Ka}$ bands. Heymsfield et al. (2016) reported on the relationships between $S$ and $Z_{e}$ at these wavelengths for the collocation periods; these are included here for purposes of comparison with the OLYMPEX data.

The methods described in Field et al. (2006) were used to mitigate the influence of particle shattering on the observations from the 2D-S and CIP imaging probes (the 2D-S had anti-shattering tips, although the correction was still done, and the HVPS shows little to no shattering signal).

There is an obvious large mismatch in the sample volumes of the particle probes compared to those of the radars. The use of the HVPS-3 probe greatly increases the sample volume compared to measurements obtained from other aircraft-radar "collocation" studies. The HVPS-3 has a sample volume that is $73 \%$ larger than that of the 2D-P probe that has been used in earlier studies. Further discussion of this point is given in section 3 and in the conclusions.

\section{b. Mass-flux conservation through the melting layer}

The second method used to derive snowfall-rateradar reflectivity relationships, referred to as the massflux (MF) method, is designed to cover a wide range of reflectivities, cloud types, and geographical locations. Consider a precipitating cloud layer with a melting layer (ML). From the top to the bottom of the ML-a thickness of 200-500 $\mathrm{m}$ (Fabry and Zawadzki 1995) — there is approximately conservation of water mass flux. Snow, with a reflectivity of $Z_{t}$ (reflectivity at the top of the ML) and precipitation rate $S$, is falling into the ML, and rain, with a reflectivity of $Z_{b}$ (reflectivity at the bottom of the ML) and precipitation rate $R$, is falling through the base of the ML. Using this idea, the $Z-S$ relationship can be estimated by deriving a $Z_{t}-R$ relationship, with $Z_{t}$ measured and $R$ obtained through retrieval algorithms. This assumption was used by Heymsfield et al. (2016), who, drawing on four years of CloudSat data, related the radar reflectivity $Z_{t}$ at the top of ML to the $R$ retrieved at the base of the ML. In the present study, the approach is further justified, with potential errors estimated, using additional CloudSat data as well as data from other 


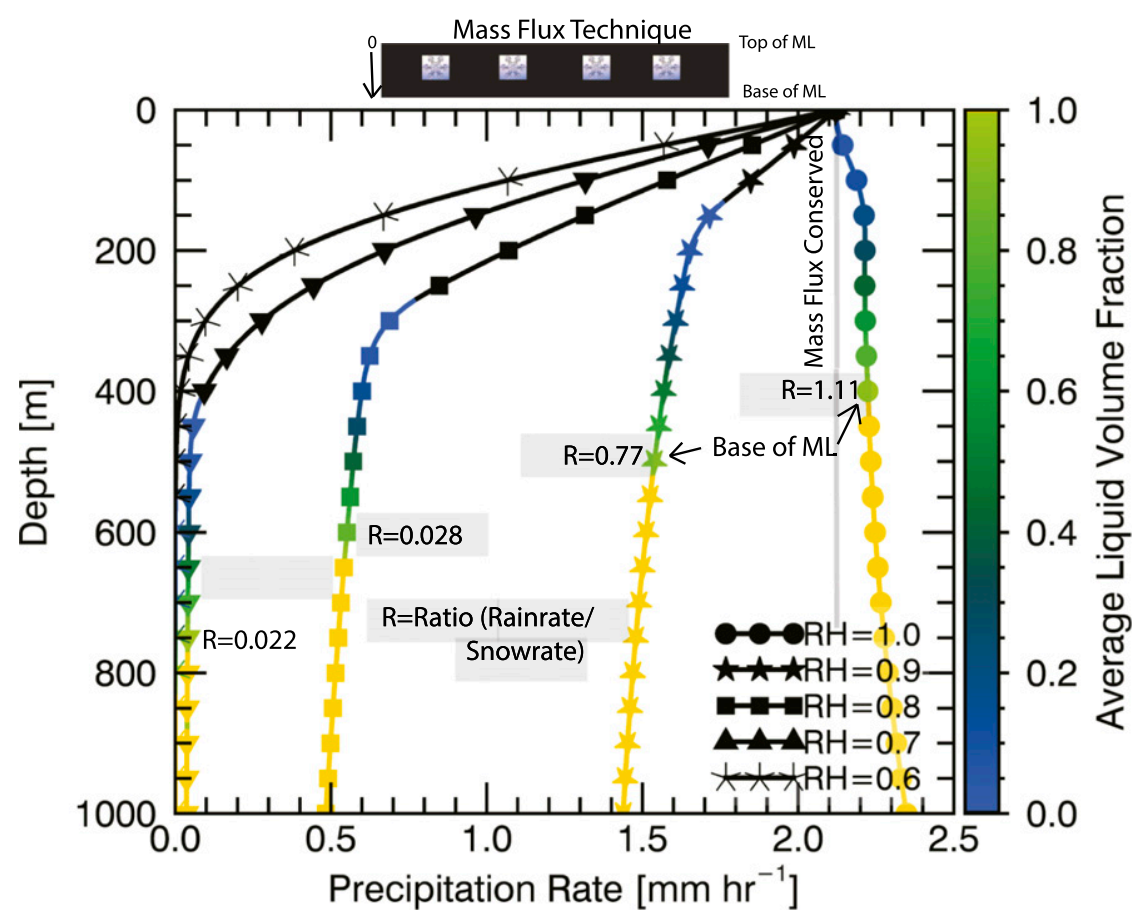

FIG. 1. Model calculations of the melting of snowfall to rainfall as a function of the depth (distance) below the start of melting with lines representing different relative humidities through the layer. The size distributions at the top of the melting layer are taken from measurements by the UND Citation aircraft in convective outflow regions during the MC3E field program in Oklahoma in May 2011. All particles start as snow, indicated by black symbols and curves, and progress through different stages of melting as the colors change (color bar shown on right side of the figure). The calculations are from A. Neumann, University of North Dakota.

spaceborne radars, thereby covering a wide range of radar reflectivities.

If the relative humidity (RH) in the ML is $100 \%$ with respect to water, there might be a small amount of condensational growth on the ice particles as they are melting because of the vapor pressure difference between water saturation at the ambient temperature and the vapor pressure over ice at the ice particle temperature. If cloud liquid water is present, there will be some growth of the melting ice and melted ice because of accretion/coalescence, but the ML will be relatively shallow. If water subsaturated conditions are present, there will be a loss of ice mass because of sublimation/ drop evaporation, and a deeper ML will result. In updrafts, a ML will not be observed unless the updrafts are particularly weak, $<1 \mathrm{~m} \mathrm{~s}^{-1}$.

To gain a better quantitative estimate of the RH in the ML and its effect on the mass-flux change through the ML, modeling simulations, followed by aircraft measurements in the ML, will now be presented.

To quantify the amount of mass-flux loss in the melting layer as a function of $\mathrm{RH}$, we draw on $1 \mathrm{D}$ microphysical simulations by A. Neumann of the University of North Dakota (Neumann 2016). The model runs begin with a population of ice particles at the top of the $0^{\circ} \mathrm{C}$ temperature level. At each time step in the model, and with the imposed $\mathrm{RH}$ and temperature profiles, the amount of melting and change in size and $V_{t}$ are derived. A complete set of equations deriving the particle temperature and gain or loss of ice mass through diffusional growth/sublimation loss are used in the calculations. The mass of sublimated or evaporated water does not add water vapor to the environment in the simulations. Thus, the simulations may overestimate the amount of mass flux lost within the melting layer. With decreasing relative humidity, the flux in the ML decreases (Fig. 1, green through black colored symbols). At water saturation, the ML is quite shallow, and even if there is some accretional growth, it is shortlived in the ice region. For RH between $90 \%$ and $100 \%$, the mass flux in the ML decreases by $<25 \%$. However, below $\mathrm{RH}=90 \%$, the mass-flux decrease is more significant, $>75 \%$ at $\mathrm{RH}<80 \%$, and the $\mathrm{ML}$ is relatively deep. 


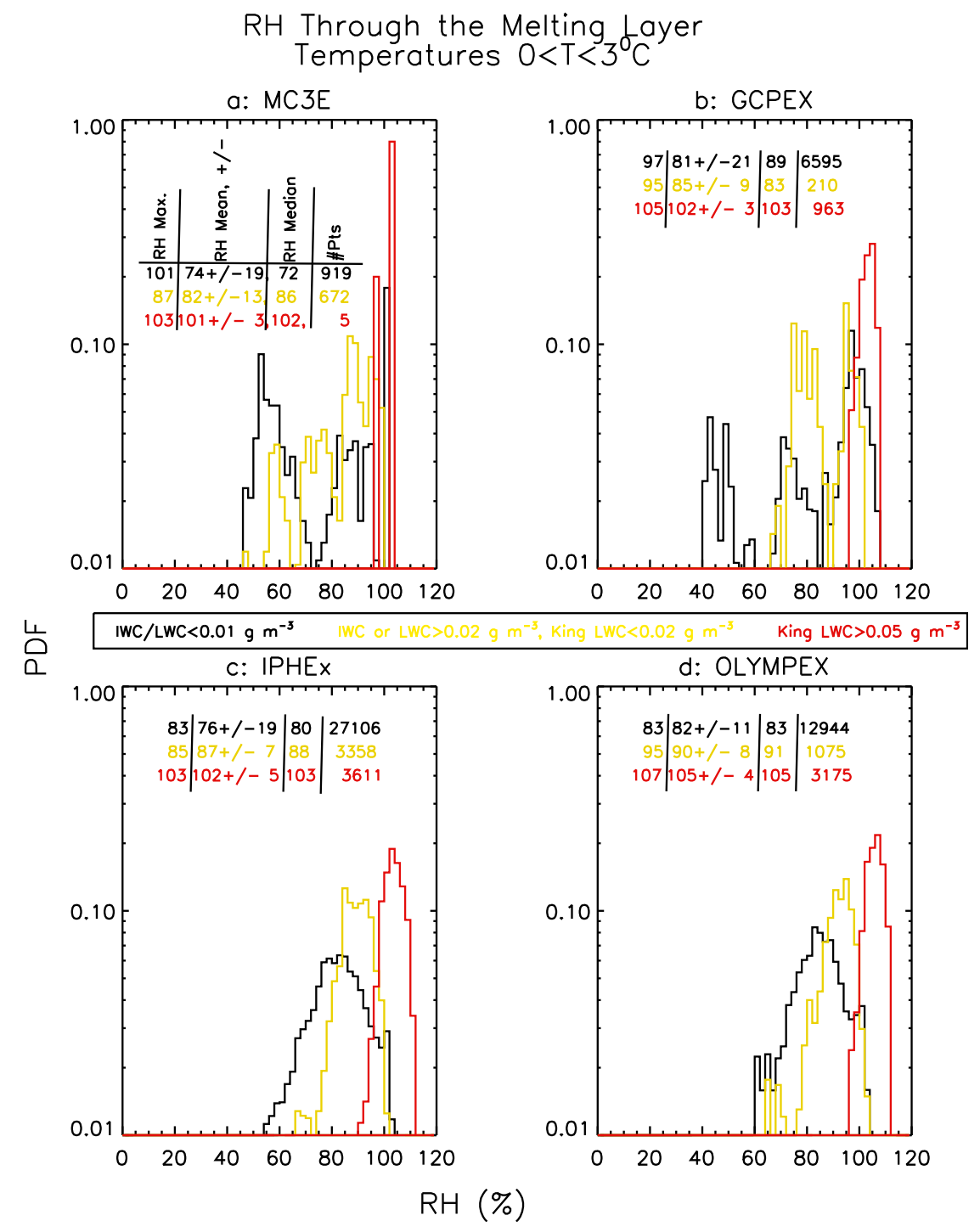

FIG. 2. Distributions of in-cloud relative humidity in the temperature range from $0^{\circ}$ to $3^{\circ} \mathrm{C}$ as measured with an Edgetech 137 chilled mirror dewpoint monitor on the UND Citation aircraft during (a)-(d) four field programs. Different colors represent different degrees of cloudiness: primarily out of cloud (black), at RH between ice and water saturation (yellow), and in the presence of liquid water (red).

What are typical relative humidities in the melting layer? McFarquhar et al. (2007) documented the RH within and below the ML from 17 aircraft Lagrangian spirals in the trailing stratiform regions of convective lines. Using the data from the spirals (kindly furnished to us by G. McFarquhar), in the temperature range $0^{\circ}-3^{\circ} \mathrm{C}$ where almost all of the melting would have occurred, the median $\mathrm{RH}$ for the cases combined was $92.8 \%$, the mean was $92.8 \% \pm 6.1 \%$, and the case with the lowest mean RH was $82.0 \%$.

Figure 2 shows the distribution of RH in the temperature range from $0^{\circ}$ to $3^{\circ} \mathrm{C}$ as measured by an $\mathrm{EG} \& \mathrm{G}$ chilled mirror dewpoint hygrometer on the University of North Dakota Citation aircraft, which flew in the Midlatitude Continental Convective Clouds Experiment (MC3E), GCPEX, the Integrated Precipitation and Hydrology Experiment (IPHEx), and OLYMPEX field campaigns. The probability density functions (PDFs) in the figure show the distribution of $\mathrm{RH}$, with values placed in bins separated by $2 \% \mathrm{RH}$. This is a statistical evaluation that involves many aircraft penetrations within and just below the ML. We consider three situations: (i) when there was essentially no ice or liquid water (IWC $<0.02 \mathrm{~g} \mathrm{~m}^{-3}$, LWC $<0.02 \mathrm{~g} \mathrm{~m}^{-3}$ ), as ascertained from the 2D imaging 
probe PSD and the King liquid water probe; (ii) when IWC $>0.02 \mathrm{~g} \mathrm{~m}^{-3}$ but King LWC $<0.02 \mathrm{~g} \mathrm{~m}^{-3}$ (arbitrary values), suggesting that the $\mathrm{RH} \sim 100 \%$; and (iii) when the King LWC $>0.05 \mathrm{~g} \mathrm{~m}^{-3}$, indicating water saturated conditions. The LWC measurements by the King Probe below about $0.02 \mathrm{~g} \mathrm{~m}^{-3}$ probably suggest no cloud liquid water; baseline drift of the instrument signal can readily account for this measured LWC. To increase the likelihood that scenarios ii and iii were associated with ice precipitation both at the top of the ML and at the sampling level, each PSD was required to contain particles $>400 \mu \mathrm{m}$ in maximum dimension.

In the top-left corner of each panel in Fig. 2, the RH at the peak of each PDF, the mean and standard deviation of the distribution, its median value, and the number of 1-s data points (about $125 \mathrm{~m}$ horizontally) are shown for each of the three scenarios. Note that the PDFs are continuous and are quite narrow when the sample size is large (Figs. 2c,d) but discontinuous when there are relatively few samples (Figs. 2a,b). Liquid water occurrence (scenario iii) is shown by the red PDF. These RH should be within about $\pm 1 \%$ of $100 \%$. Given that there is a distribution of $\mathrm{RH}$, which for the various field programs peaked at $103 \%-107 \%$ but with median values of $102 \%-105 \%$, this would suggest that the RH measurements are about $2 \%-5 \%$ high. The mean values would suggest that on average the $\mathrm{RH}$ are $\sim 2 \%$ high, and the spread of approximately $4 \%$ about the mean is the result of temperature errors and chilled mirror time lag. The mean $\mathrm{RH}$ in cloud but with no liquid water (scenario ii) are $82 \%-90 \%$, with a spread of $\sim 8 \%$. In cloud-free air (scenario i), there is much more variability in the $\mathrm{RH}$ PDFs, but in general they are quite high.

To summarize, when the sample size is large, the RH distributions in the regions with ice but no cloud liquid water have median values of $\sim 90 \%$, and when cloud liquid water is present this increases to $100 \%$. From Fig. 1, it is therefore reasonable to suggest that the loss or increase in the precipitation rate from the snow to the rain regions is $<25 \%$, except when liquid water is present. The depth of the melting layer is a proxy for the average relative humidity in the layer. Obviously, more data from rawinsondes when it is known that cloud is present are clearly needed to refine this estimate.

Using the MF method we examine three satelliteborne radar datasets: CloudSat, TRMM, and GPM.

CPR makes near-nadir-pointing observations with a footprint of about $1.7 \mathrm{~km}$ along track by $1.3 \mathrm{~km}$ cross track between $82^{\circ} \mathrm{N}$ and $82^{\circ} \mathrm{S}$. Data used for these analyses cover the period from December 2007 through December 2008. Information about the meteorological state comes from reanalysis products of the European Centre for Medium-Range Weather Forecasts (ECMWF) that have been collocated to the CloudSat radar profiles. The CloudSat snowfall data were produced via a retrieval method similar to that used by the CloudSat 2C-SNOW-PROFILE (2C-SP) version release 4 (R04) algorithm (Wood et al. 2013), but modified to perform retrievals above the melting layer when rain or mixedphase precipitation is reaching the surface. As does the unmodified algorithm, this 2C-SP-mod retrieval algorithm estimates vertical profiles of the probability density functions of snow PSD parameters using explicit a priori assumptions about snow particle microphysical and scattering properties. The estimates of the PSD parameters are then used along with the microphysical properties to construct the vertically resolved snowfall rate. The $2 \mathrm{C}-\mathrm{SP}$ data are from the $\mathrm{R} 04$ product. A retrieval is performed if the 2C-PRECIP-COLUMN (2C-PC) product (Haynes et al. 2009) indicates rain or mixed-phase precipitation is reaching the surface and reflectivities above the $0^{\circ} \mathrm{C}$ level, as determined from the ECMWF-AUX product, are substantial enough to suggest snowfall $(>-15 \mathrm{dBZ})$. Rainfall rates at the surface and below the $0^{\circ} \mathrm{C}$ height are estimated from the results of the 2C-RAIN-PROFILE (2C-RP) R04 product (L'Ecuyer and Stephens 2002; Lebsock and L'Ecuyer; Lebsock et al. 2011). The 2C-RP retrieves profiles of liquid water content for CPR profiles identified by $2 \mathrm{C}$ $\mathrm{PC}$ to be raining. For cold rain, the 2C-RP retrieval assumes a Marshall-Palmer size distribution (Marshall and Palmer 1948). For the raining profiles analyzed in this work, the rain rates below the melting level and at the surface were estimated from the liquid water contents using the assumed Marshall-Palmer distribution and determining the slope of the size distribution. From that, rain rates were found by applying a raindrop fall speed parameterization (Szyrmer and Zawadzki 1999).

The TRMM data consist of radar reflectivity measurements from the single Ku-band precipitation radar (PR) covering the latitude range from $36^{\circ} \mathrm{N}$ to $36^{\circ} \mathrm{S}$ for the period 1998-2014. The attenuation-corrected reflectivity and rain-rate retrievals are based on the 2A25 algorithm (Iguchi et al. 2009). The convective versus stratiform separation heights of the bright band and freezing level are derived from the $2 \mathrm{~A} 23$ algorithm (Awaka et al. 2009). The vertical resolution of the reflectivity and rain retrievals is $250 \mathrm{~m}$ and the horizontal radar pixel size is about $4.2 \mathrm{~km}$ before the TRMM orbit boost (August 2001) and $4.5 \mathrm{~km}$ after the boost. The data used in this study are from January 1998 to September 2014. Level 3 retrieval processing products are used.

The GPM satellite measurements cover approximately $65^{\circ} \mathrm{S}-65^{\circ} \mathrm{N}$ in a non-sun-synchronous orbit. The dual-polarization radar consists of $\mathrm{Ku}$ - and Ka-band channels. The data product used here is derived from 
level $2 \mathrm{~A}$ processing, containing radar reflectivities and retrieved precipitation rate and phase (Iguchi et al. 2010). Precipitation rate is retrieved from the radar reflectivity factor corrected by a hybrid of the HitschfeldBordan (Hitschfeld and Bordan 1954) method and a surface reference method. The snowfall retrievals used in the study are based on the combined $\mathrm{Ku}$ - and $\mathrm{Ka}$ band observations. The reflectivities shown in the figures are from $\mathrm{Ku}$ band. The horizontal resolution is about $5 \mathrm{~km}$. The data are from 8 March 2014 to 31 March 2015. The use of dual-frequency radar places more constraints on the retrieval algorithms and hence should be more accurate than for the TRMM retrievals.

The TRMM and GPM rain-rate retrievals are based on empirical relationships reported in Kozu et al. (2009), separated into stratiform and convective rain types.

\section{Results}

This section presents the results obtained from the two methods, OBS and MF, described above. First, using the OBS method, and drawing on the in situ aircraftoverflying radar collocation observations, we develop $Z-S$ relationships at multiple radar wavelengths. Then, using data and retrievals from radars on the CloudSat (W band), GPM (Ku and Ka bands), and TRMM (Ku band) satellites, with the MF method we develop relationships between the ice water content or the snowfall rate and radar reflectivity over a wide range of reflectivities.

\section{a. Analysis using collocation datasets}

By comparing the radar reflectivity measurements at the three different wavelengths from the OLYMPEX field program, both in the ice and liquid regions, the following information on radar-specific, and thereby PSD-size specific, can be identified: 1) the reflectivities where non-Rayleigh effects become significant and 2) where attenuation of the radar signals becomes appreciable. The latter is more likely for $\mathrm{W}$ band than $\mathrm{Ku}$ band, for example. Reflectivities measured during OLYMPEX for $\mathrm{Ka}$ and $\mathrm{W}$ bands are related to the measured reflectivities at $\mathrm{Ku}$ band (Fig. 3). For temperatures above $3^{\circ} \mathrm{C}$, where the ice particles should be fully melted, there appears to be a few $\mathrm{dB} Z$ low bias in the Ka-band reflectivities, which could be due to the effects of attenuation by the rain (Fig. 3a). NonRayleigh effects begin to become significant somewhere between 28 and $30 \mathrm{dBZ}$. Attenuation of the $\mathrm{W}$-band measurements by rain appears to be appreciable throughout, with some evidence that non-Rayleigh effects become significant at reflectivities above about $10 \mathrm{~dB} Z$ in ice. In the ice regions, there does not appear to
OLYMPEX Ku, Ka and W-band data, Collocations
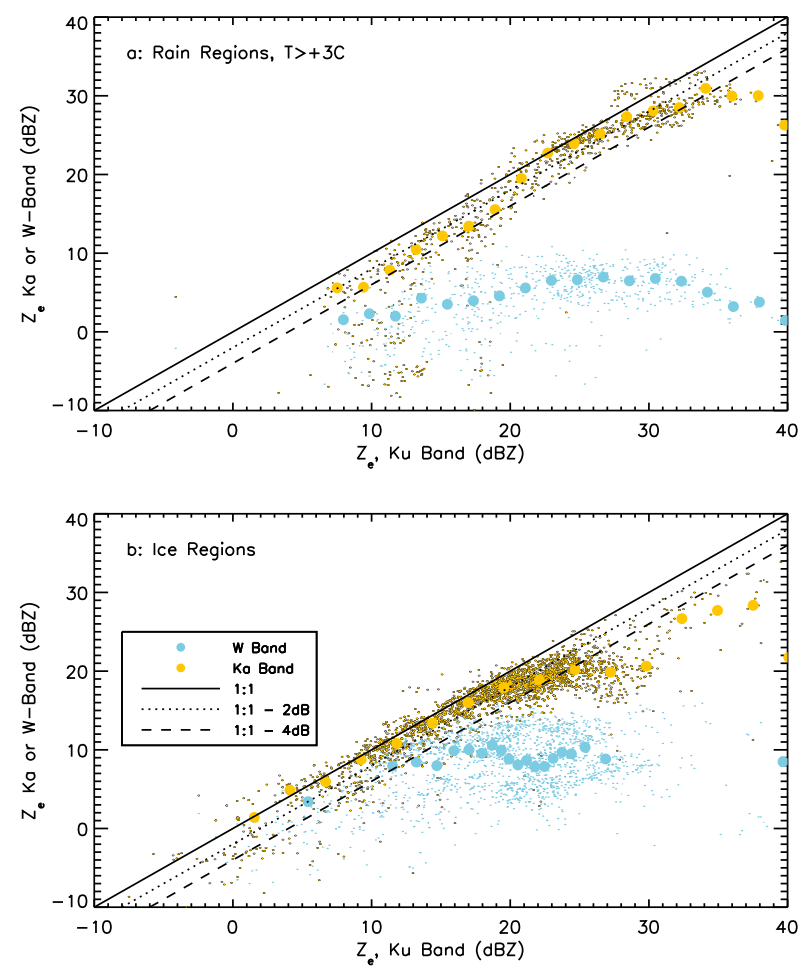

FIG. 3. Data obtained from collocations of the UND Citation in situ aircraft and the NASA DC-8 with APR-3 on board during the OLYMPEX field program: (a) rain regions and (b) ice regions. The Ku-band data are on the abscissa; Ka- or W-band data are on the ordinate. The W-band data are likely to be significantly attenuated in rain, less so in ice.

be appreciable attenuation for Ka band (Fig. 3b). NonRayleigh effects become significant at about 18-20 dBZ at Ka band and $14 \mathrm{dBZ}$ at $\mathrm{W}$ band.

As a check on the quality of the PSD sizing and mass-dimensional relationships for OLYMPEX, Fig. 4 compares calculated to measured radar reflectivities in regions above $3^{\circ} \mathrm{C}$ where the particles are almost certainly all liquid. Two sets of radar backscatter cross sections are considered, Rayleigh spheres and Mie spheres. At Ku band, there should be little if any non-Rayleigh scattering for most reflectivities sampled (Fig. 4a). What is noted is that, although the calculated and measured $Z_{e}$ show the same trend, the former is offset by about $3 \mathrm{~dB}$. Simulations we have conducted of raindrops as imaged by the particle probes demonstrate that drop diameters are oversized for rain by about 1 pixel, corresponding to about $150 \mu \mathrm{m}$, which is a small oversizing, especially for the larger particles. This oversizing would affect estimates of $R$ by a factor of between 1.1 and 1.4, depending on 
OLYMPEX, Measured vs Calculated Reflectivities, T>3C

a: Ku Band

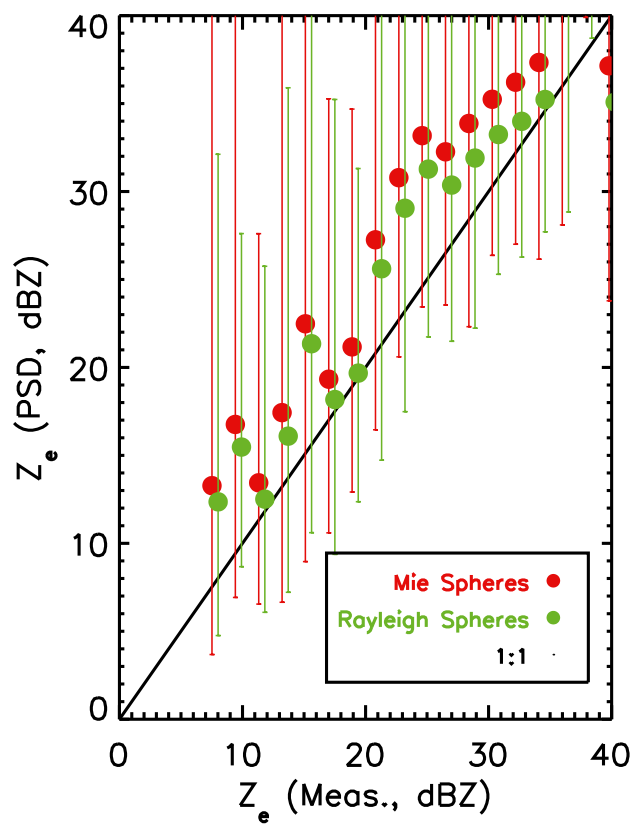

c: W Band

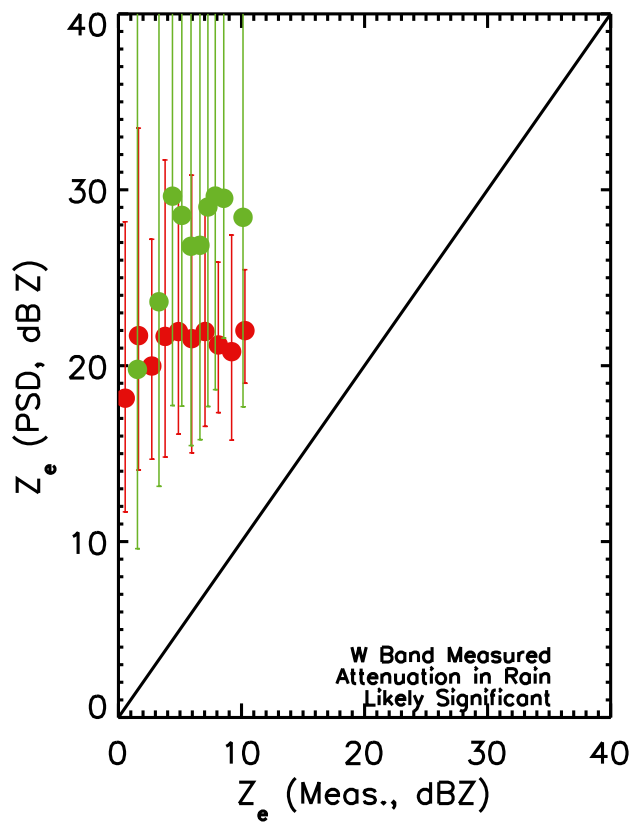

b: Ka Band

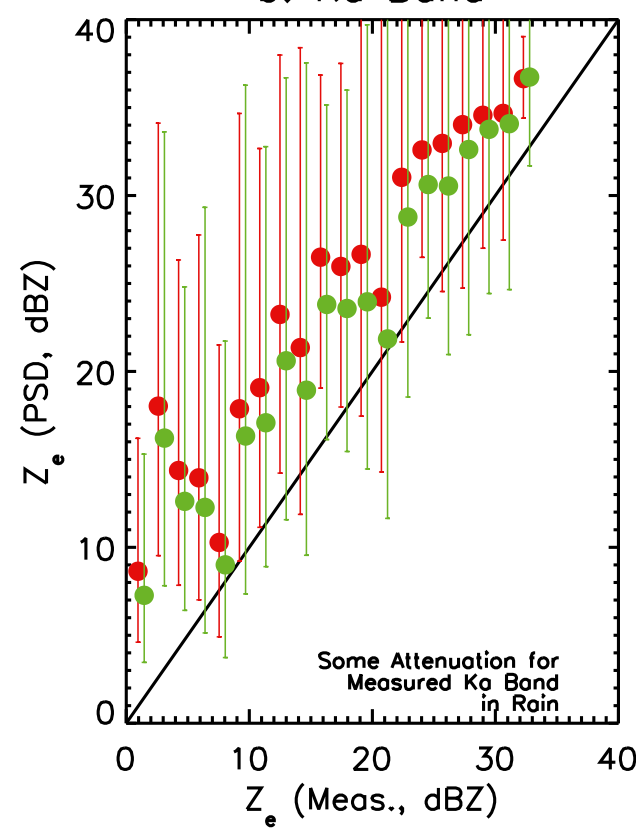

d: $d W R$

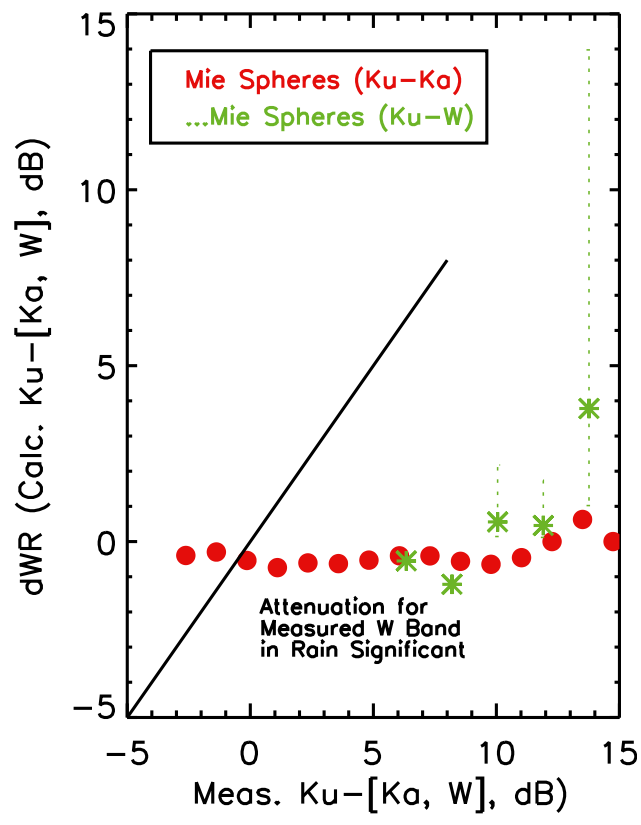

FIG. 4. Measured vs calculated reflectivities during OLYMPEX collocations in rain regions $\left(T>3^{\circ} \mathrm{C}\right):(\mathrm{a}) \mathrm{Ku}$ band, (b) Ka band, (c) W band, and (d) dWR. Panels (c) and (d) show significant attenuation at W band. At small particle sizes the error in $\mathrm{dBZ}$ increases.

the shape of the PSD, which is quite significant. For Ka band, the error for the calculations using Mie spheres is more extensive than for $\mathrm{Ku}$ band, again in part because of oversizing, which factors directly into the Mie backscatter correction; furthermore, some attenuation at Ka band is not considered, which would increase $Z_{e}$ (Fig. 4b). At W band, the large mismatch between the measured and calculated reflectivities is likely due to the lack of correction for attenuation (Fig. 4c). There are almost no dual-wavelength-ratio (dWR) values, 


\section{OLYMPEX, Measured vs Calculated Reflectivities, $T<O C$}
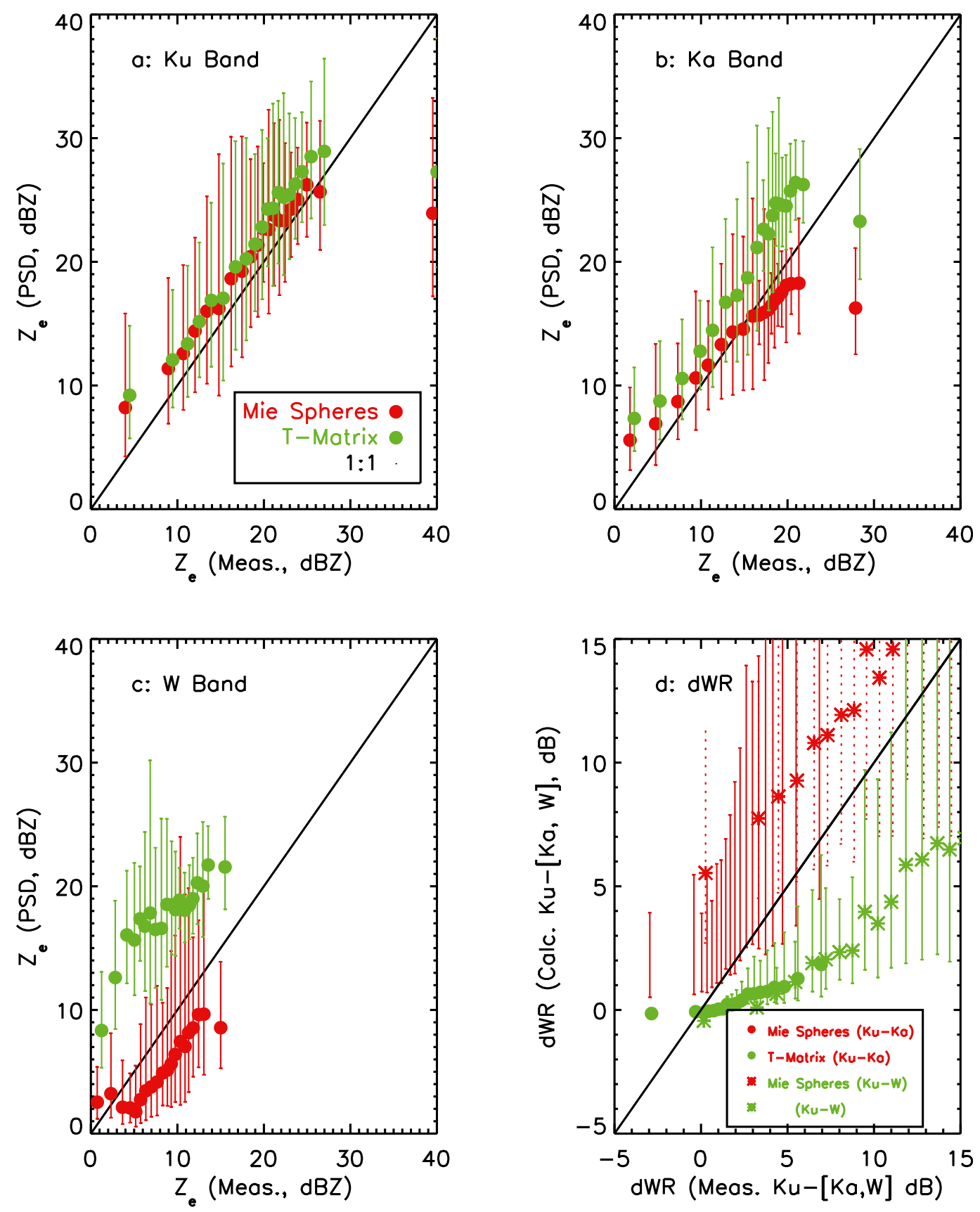

FIG. 5. As in Fig. 4, but for ice-phase regions.

except at $\mathrm{W}$ band at reflectivities above $10 \mathrm{dBZ}$ (Fig. 4d).

Figure 5 shows the results for the collocations at temperatures $<0^{\circ} \mathrm{C}$, where the forward modeling of the in situ data to yield radar reflectivities includes both Mie spheres and scattering by oblate spheroids of aspect ratio 0.6 employing the T-matrix approach of M07. For $\mathrm{Ku}$ band, the trends found for the calculations are higher by a median of $1.52 \mathrm{dBZ}$ of the measurements, within the absolute calibration confidence interval of the measurements (Fig. 5a). The calculations suggest that the mass-dimensional relationship we are using is 


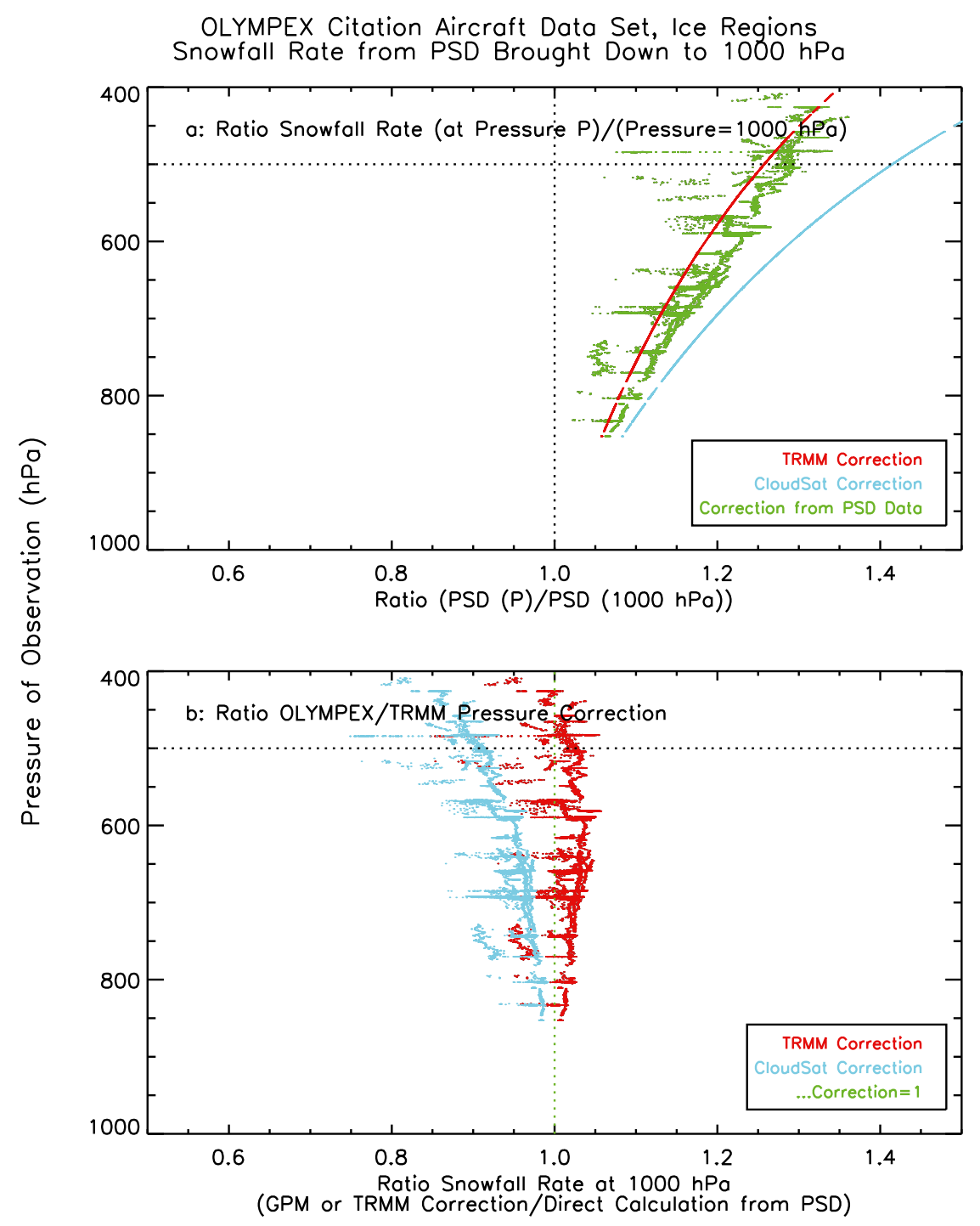

FIG. 6. Using the OLYMPEX PSD to derive snowfall rate, correction of $S$ for the effects of atmospheric pressure on terminal velocity for: TRMM (red), CloudSat (blue), and PSD data (green). Altitude-dependent corrections for TRMM-GPM are applied to the OLYMPEX Citation altitudes to derive the corresponding correction that would have been used by that algorithm, and pressure is used to derive the corresponding CloudSat correction. (a) Ratio of $S$ derived from the OLYMPEX PSD at the pressure level to that derived at $1000 \mathrm{hPa}$. (b) Ratio of correction at $1000 \mathrm{hPa}$ to that derived from the detailed calculations.

accurate. The calculated reflectivities are also consistent with measurements at Ka band with a median difference of $0.69 \mathrm{~dB} Z$ across all reflectivities, although there is a large dip above about $20 \mathrm{~dB}$, where the T-matrix approach underestimates the reflectivities (Fig. 5b). At W band, the use of $\mathrm{T}$ matrix with spheroids overpredicts the reflectivities, and the Mie approach slightly underestimates them (Fig. 5c); it is possible that the particles are more spherical than 0.6, the value used for oblateness in the T-matrix calculations. Nonetheless, it is surprising that there is a significant non-Rayleigh effect at reflectivities below $10 \mathrm{~dB} Z$. The measured and calculated dWR largely follow the offset of the calculations from the measurements at reflectivities where non-Rayleigh effects are rather small but show large differences where they are significant (Fig. 5d).

The results presented in Fig. 5 indicate that there is good agreement between the calculated and measured reflectivities in the regions of snow, in particular for $\mathrm{Ku}$ and $\mathrm{Ka}$ band. Based on our simulations of the response of particle probes to ice, we suggest that the particle probe oversizing problem is negligible in ice. 


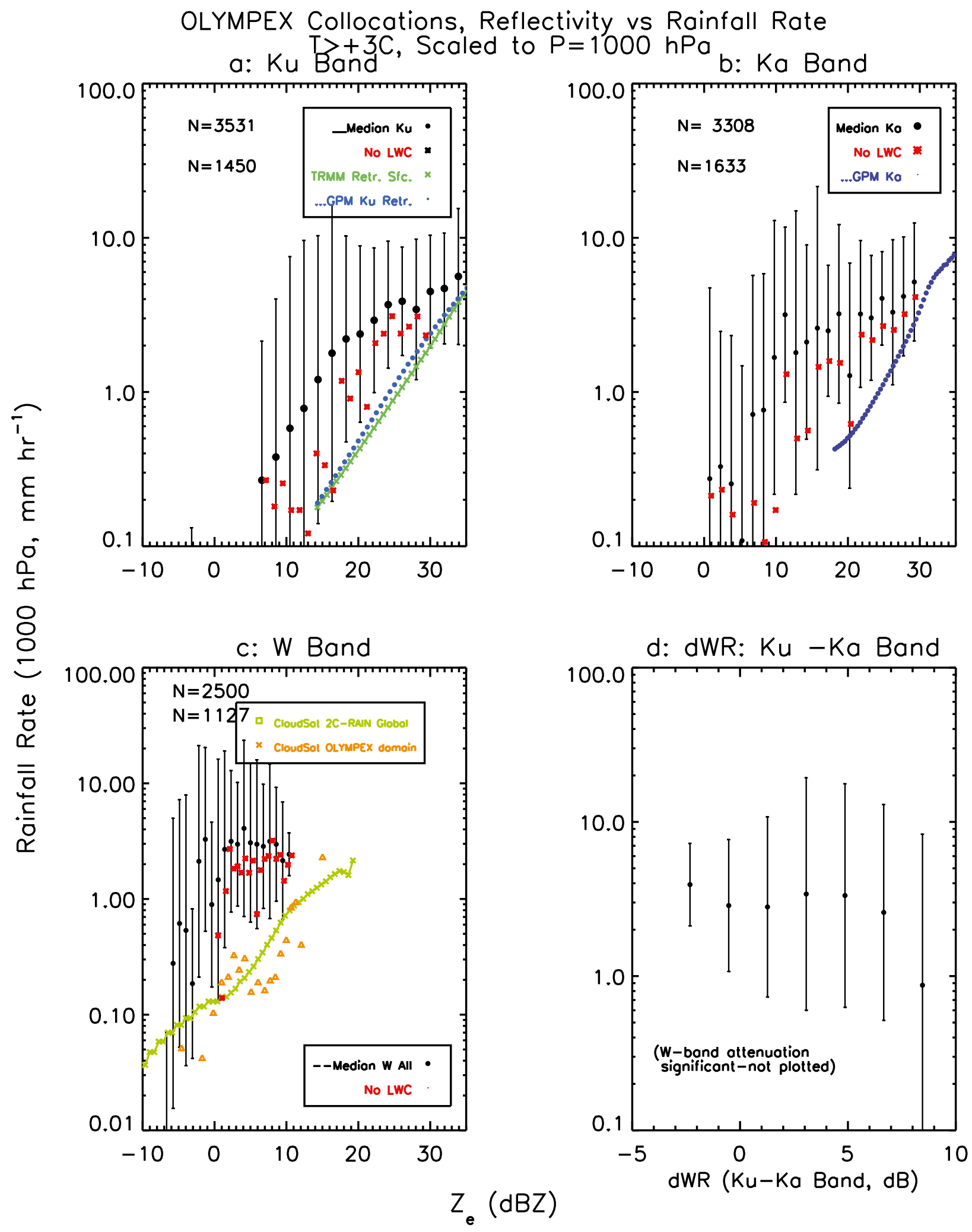

FIG. 7. Measured reflectivities vs calculated rainfall rates from the OLYMPEX collocations: (a) Ku band, (b) Ka band, (c) W band, and (d) dWR with median values in black, no LWC in red, TRMM in dark green, GPM in blue, CloudSat Global in light green, and CloudSat Olympex in orange. Attenuation may be significant in (c) and (d) and to a lesser extent in (b). The rainfall rates are adjusted downward to a pressure level of $1000 \mathrm{hPa}$ to compensate for pressure effects. The number of 1 -s collocation data points $(N)$ are shown in (a)-(c); the top number refers to all 1-s collocations and the bottom number to the number only in regions with no cloud water. The numbers can vary between panels because of malfunctions of each of the radars or otherwise because of unreliable data. 


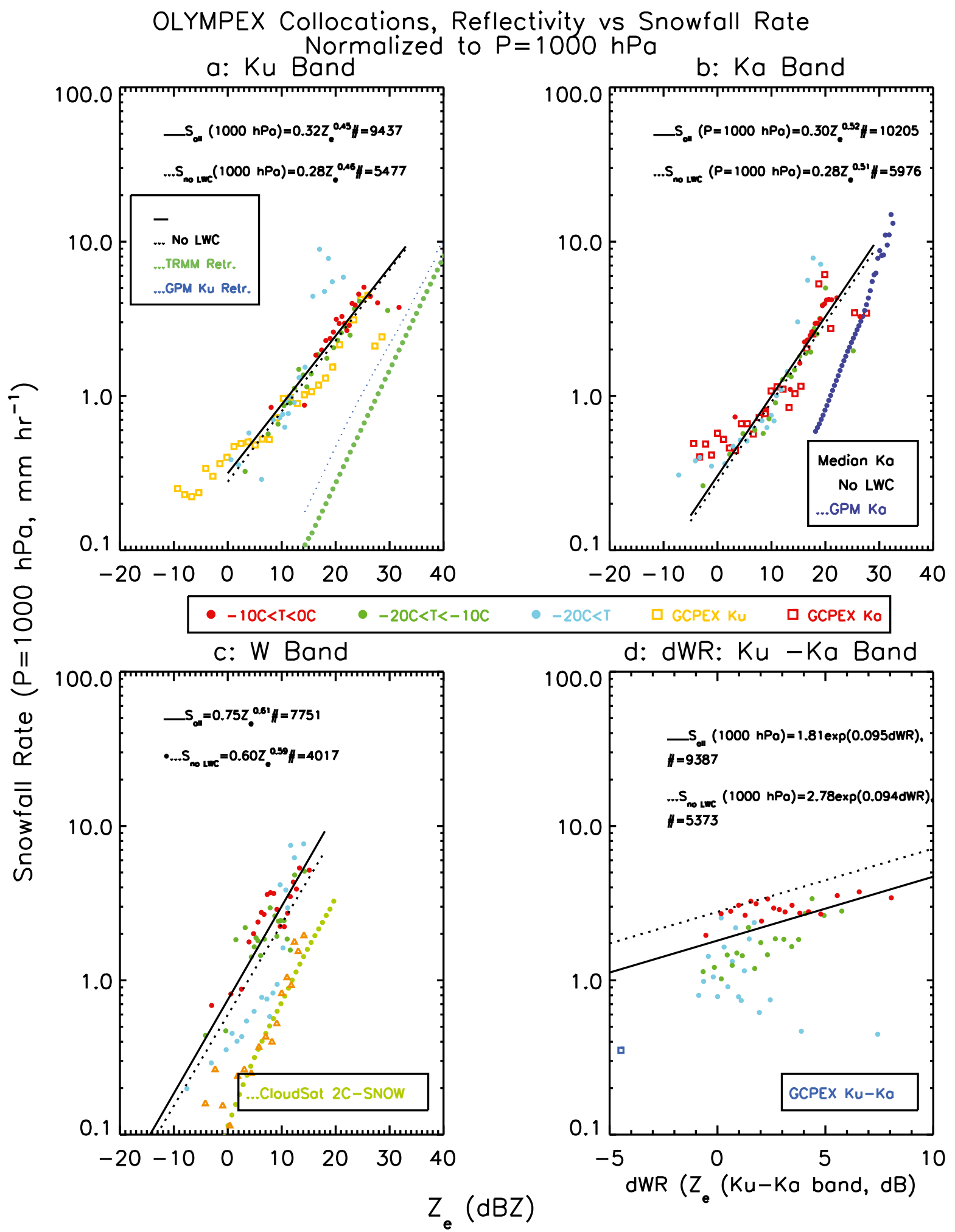

FIG. 8. As in Fig. 7, but for ice-phase regions. The two sets of data shown in each panel are for those periods when there is and is not liquid water present. Curve fits to the data are shown. 


\section{Summary of OLYMPEX/GCPEX Collocation Data}
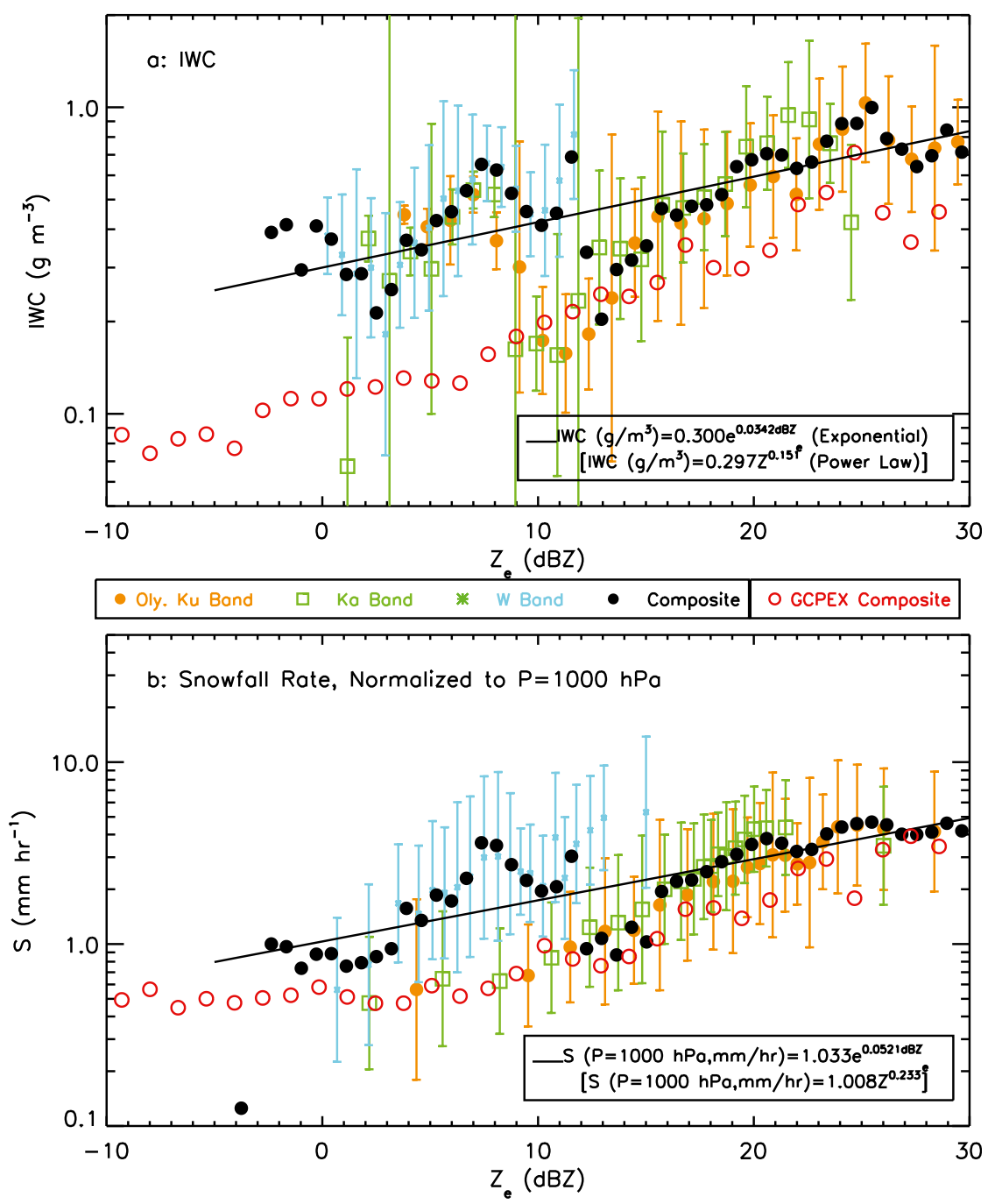

FIG. 9. Summary of collocation data for all wavelengths combined, along with a composite that represents a summary of the data from the three wavelengths. Curve fits to the data are shown. (a) IWC with two curves listed: one an exponential, which fits the data quite well, and the second, a power law with the equation in brackets and (b) $S$, adjusted to a pressure level of $1000 \mathrm{hPa}$.

Furthermore, it is reasonable here to address the question of the large mismatch in the sample volumes of the particle probes relative to the radar. To address this question, the radar reflectivity gradient through each of the flights was examined; large gradients might suggest that the mismatch would result in errors in the comparisons. Of the 22 flights in the OLYMPEX dataset, only flights $2,6,12,17$, and 21 had periods when there were appreciable gradients in the reflectivity. Therefore, it is reasonable to assume that the in situ versus radar comparisons shown herein are reliable.
For the comparison of precipitation rates derived from the OLYMPEX, TRMM, GPM, and CloudSat datasets from a range of altitudes (pressure levels) to be more meaningful, it is important to adjust the precipitation rates from all datasets to a common pressure level, $1000 \mathrm{hPa}$, to account for the increase in $V_{t}$ and thus $R$ with altitude (with decrease of pressure $P$ ). For example, during OLYMPEX the median pressure at a temperature from $-4^{\circ}$ to $-6^{\circ} \mathrm{C}$ was $700 \mathrm{hPa}$, whereas in the tropics the pressure is closer to $510 \mathrm{hPa}$. Our calculations indicate that this pressure difference will result in a $17 \%$ higher precipitation rate for OLYMPEX. Most 


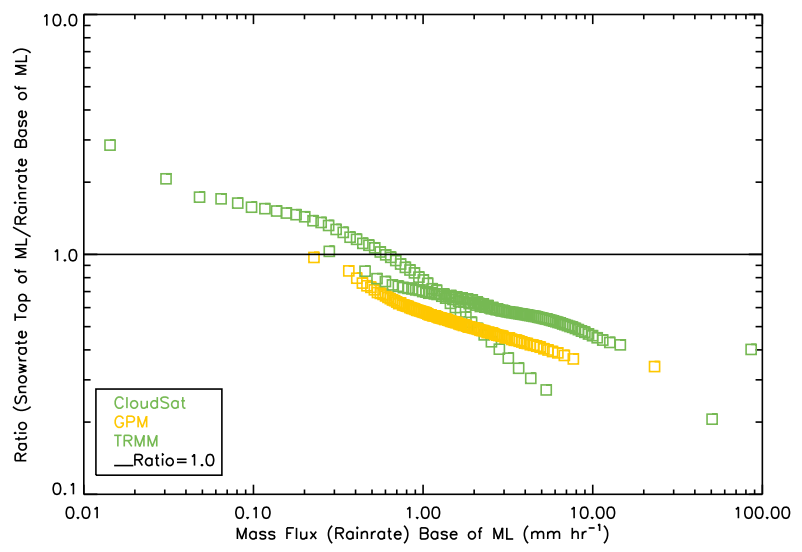

FIG. 10. The relationship between snowfall rate at the top of the melting layer and the rain rate at the base of the melting layer as a function of the rain rate at the base of the melting layer from the CloudSat and TRMM (green) and GPM (orange) datasets, normalized to a pressure level of $1000 \mathrm{hPa}$

pressure adjustments to the raindrop terminal velocities generally follow the Foote and Du Toit (1969) relationship $(P / 1000)^{0.5}$, as is the case for the terminal velocity relationship based on Szyrmer and Zawadzki (1999) that we use in our calculations of rainfall rate from liquid water content for the $2 \mathrm{C}$-RP dataset. The 2C-SP-mod uses a physically based fall speed model (Mitchell and Heymsfield 2005), but we approximate the adjustment to $1000 \mathrm{hPa}$ following Foote and Du Toit as well. TRMM and GPM use a correction that is based on altitude (TRMM Precipitation Radar Team 2011). Figure 6a shows the pressure adjustment based on the size distributions and particle shapes derived from the $2 \mathrm{D}$ probes from this study, as well as the adjustments using the TRMM and GPM algorithms based on altitude, and the Foote and Du Toit pressure adjustment applied to the CloudSat datasets. The results using the TRMM algorithm are quite close to those derived here, with a slight overestimate, whereas the Foote and $\mathrm{Du}$ Toit correction applied to the CloudSat datasets produces values that are about $10 \%$ too low (Fig. 6b).

It is useful to compare the $Z-R$ and $Z-S$ relationships from the OLYMPEX dataset to similar relationships developed from the TRMM, GPM, and CloudSat datasets. The comparisons are shown for rain (Fig. 7) and snow (Fig. 8). Although convective elements were included in the results for GPM and TRMM, their impact on the results is insignificant; of the GPM (TRMM) points, only $1.5 \%(0.23 \%)$ were within regions where the rain-type flag indicated convection. The data for the satellite-derived retrievals for rain are taken at the base of the ML, relatively close to where the Citation flew, and the snow at the top of the ML, also close to the Citation data. The $Z-R$ relationship found for rain in two TRMM datasets, in which $R$ for one set is taken at the base of the melting layer and $R$ for the second from just above the ground, show a similar trend but differ by an average of $7 \%$ (not shown). The results are similar for the GPM Ku-band data. For Ka band, the agreement between the collocation data and GPM Ka-band retrievals is better, but this may be because attenuation by rain is reducing the reflectivity relative to the in situderived rainfall rate. For $\mathrm{W}$ band, the CloudSat retrieved rainfall rates are considerably below those from the collocations, even though attenuation of the latter may have been significant. In the absence of cloud liquid water, the collocation dataset has lower rainfall rates than when the liquid water regions are included. For rain regions, currently there is little useful information on the dual-wavelength ratio because of attenuation at both $\mathrm{Ka}$ and $\mathrm{W}$ bands.

Comparisons of the assumed PSDs for the retrievals and the collocations as a function of reflectivity might provide insight into the reasons behind the differences between the rainfall rates derived from the collocations and from the radar retrievals. As an example, the 2C-RP assumptions of a Marshall-Palmer DSD for these stratiform cold rain cases may not be consistent with the PSDs that occur in higher-latitude conditions or with the unevolved rain PSDs present immediately below the melting layer.

Snowfall rates are related to the measured reflectivity and shown in several temperature intervals for the collocation times for OLYMPEX, as well as those from the GCPEX collocations (Fig. 8). The OLYMPEX and GCPEX collocation data yield similar $Z-S$ relationships (Figs. 8a,b), with a power-law representation yielding an exponent of about 0.5 . Temperature does not have a significant effect on the relationships, and the relationships developed for those instances with and without the presence of liquid water are similar (Figs. 8a-c). A welldefined relationship is noted between the dWR and snowfall rate, although there appears to be a $1-\mathrm{dB} Z$ offset that might be due to a calibration difference between the APR-3 Ku- and Ka-band data. Compared to the OLYMPEX data, the satellite-derived relationships are about a factor of 5-10 lower, with the exception of the GPM Ka-band data. It is unclear why the results for GPM Ka-band retrievals for both rain and snow compare better than the Ku-band retrievals versus the observed collocations. For a given $\mathrm{dB} Z$ value, the snowfall rates for GCPEX are generally lower than those for OLYMPEX.

To put the present results in the context of relationships developed in earlier studies, Fig. 9 presents both the IWC and $S$ collocation data as a function of the radar reflectivity for the three wavelengths combined. 


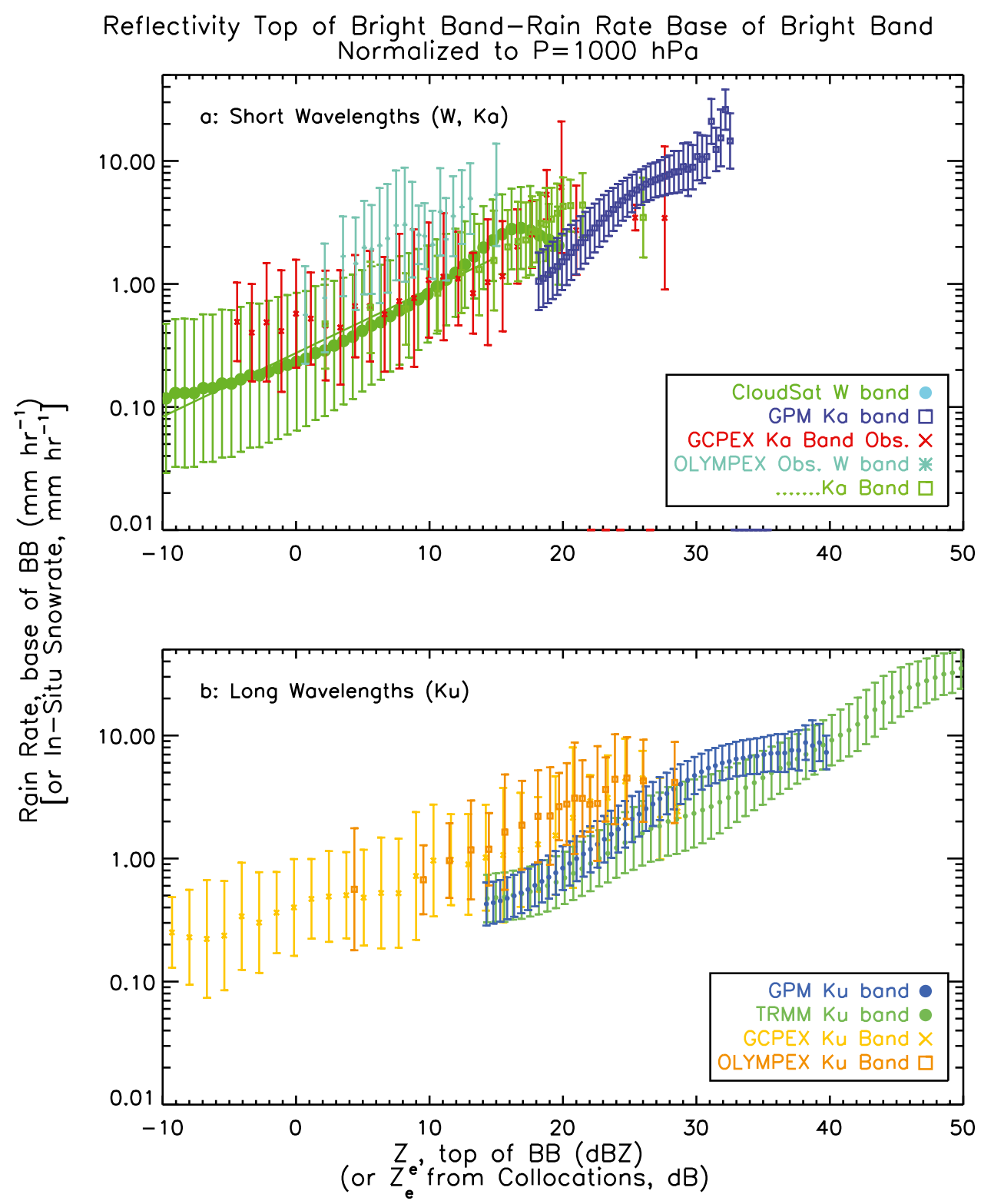

FIG. 11. Relationships found between the retrieved rainfall rate at the base of the melting layer and the measured reflectivity at the top of the melting layer from CloudSat, GPM, and TRMM datasets. Also plotted are data from GCPEX and OLYMPEX. (a) W and Ka bands. (b) Ku band.

Only data from the temperature range from $0^{\circ}$ to $-10^{\circ} \mathrm{C}$ are used so as to facilitate a comparison with the mass-flux method discussed later. The IWC is shown so as to provide a comparison with earlier IWC- $Z_{e}$ relationships. To minimize the effect of non-Rayleigh scattering, the data for the three wavelengths from OLYMPEX are combined by considering W-band reflectivities $<10 \mathrm{dBZ}$, the Ka-band data from the minimum detectable reflectivity to $25 \mathrm{dBZ}$, and the $\mathrm{Ku}$-band data from the minimum detectable to $30 \mathrm{~dB} Z$. Median values of IWC and $S$ are derived in intervals of
$1 \mathrm{dBZ}$ from the combined dataset, with the IWC increasing nearly linearly with $Z_{e}$. A linear relationship between IWC and $Z_{e}(\mathrm{~dB})$ is fit over the range from -5 to $30 \mathrm{~dB} Z$ to yield coefficients for an exponential fit (Fig. 9a). Most earlier IWC- $Z_{e}$ are in the form of a power law IWC $=a(Z)^{b}$, where $a$ and $b$ are coefficients. The results of our study, if fitted to a power-law form (shown in brackets), yield $a=0.334$ and $b=0.141$ (IWC: $\mathrm{g} \mathrm{m}^{-3} ; Z_{e}: \mathrm{mm}^{6} \mathrm{~m}^{-3}$ ).

Figure 9b shows the relationship between $S$ and $Z_{e}$ for each wavelength separately and for the three 


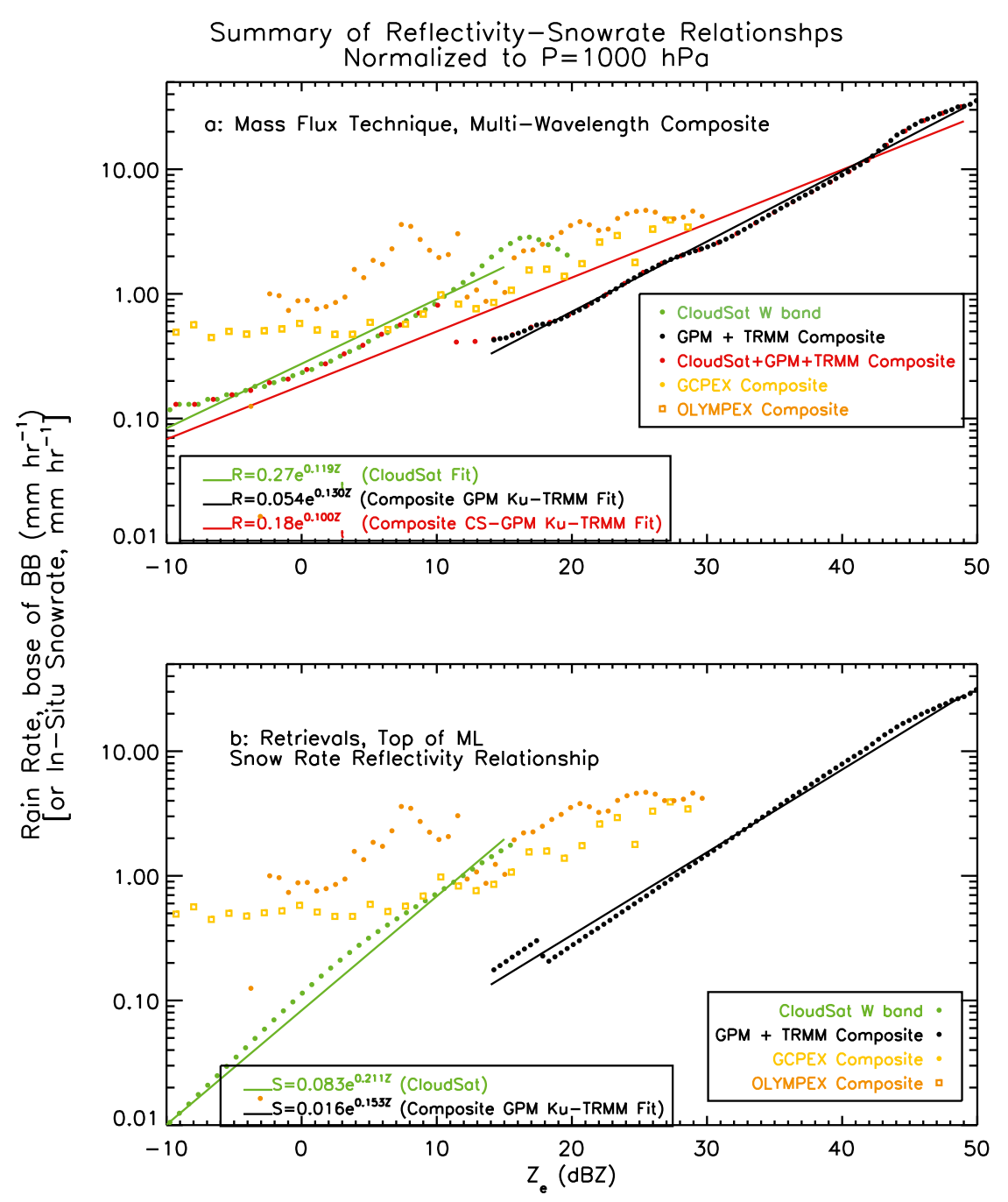

FIG. 12. Summary of (a) $S-Z_{e}$ relationships found from the mass-flux technique and (b) from the retrievals. The GPM Ku-band and TRMM data are combined to produce the results shown. The kink in that composite relationship at about $18 \mathrm{dBZ}$ is the result of combining the two datasets with different minimum detectable reflectivities. In (a), curve fits are shown for the CloudSat, the GPM-TRMM composite, and the composite of the three, and in (b) for the former two.

wavelengths combined. A curve fit to those data as in Fig. 9a is listed and plotted in the figure. In terms of a power law, the relationship becomes $S\left(\mathrm{~mm} \mathrm{~h}^{-1}\right)=$ $1.008 Z^{0.233}$ (shown in brackets).

The power-law relationship given above (see Fig. 9b) can be compared to those presented for the Tropical Clouds, Convection, Chemistry and Climate (TC4) data (primarily anvils and outflow cirrus) in Heymsfield et al. (2016). For X band from TC4, where the measured reflectivities are in the range from 0 to $10 \mathrm{~dB} Z$, the ratio of the relationship derived there (Fig. 12b) is $\sim 0.4$ at $0 \mathrm{dBZ}$ and $\sim 0.5$ at $10 \mathrm{~dB} Z$. For $\mathrm{W}$ band, where the TC4 measurements were in the range from about -10 to $10 \mathrm{~dB} Z$, the ratios are from $\sim 0.3$ to 0.5 . The comparisons are quite good, considering the differences in the cloud types observed.

\section{b. Conservation of mass flux}

A potentially more general radar reflectivity $Z_{e}-S$ relationship than that developed from the collocation data can be developed by relating $Z_{t}$ above the melting layer to $R$ below the melting layer. Here, we use data from radars on board CloudSat (W band, corrected for gaseous attenuation), GPM ( $\mathrm{Ka}$ and $\mathrm{Ku}$ band), and TRMM (Ku band).

As discussed in section 2, there should be conservation of mass flux across the melting layer. Thus, the 

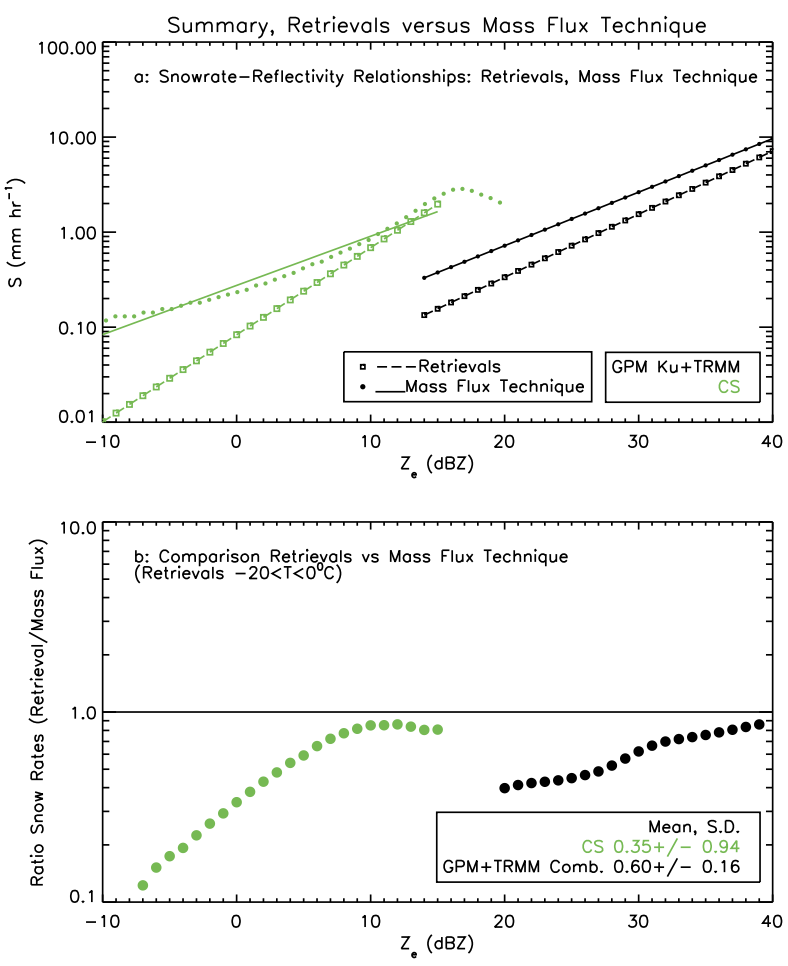

FIG. 13. (a) $S-Z_{\mathrm{e}}$ relationships derived from the MF method and the standard GPM-TRMM combined retrievals. The fitted curves rather than the mean values are shown. (b) Ratio of retrieved to MF method as a function of radar reflectivity. The curve fit relationships are listed in Table 2.

retrieved snow rates at the top of the melting layer should be approximately the same as the rain rates at the base of the melting layer. Bennartz and Petty (2001) use the idea of conservation of mass flux to constrain particle size distribution changes across the melting layer for a microwave remote sensing study. A rain rate smaller than the snowfall rate might suggest that there is considerable sublimation/evaporation in the melting layer and a decrease in the mass flux, whereas rain rate larger than the snowfall rate might suggest increases in the mass flux; large differences between retrieved estimates of $S$ and $R$ might suggest errors in the snow- or rain-rate retrieval algorithms. One caveat for the massflux method has to do with the horizontal displacement of a population of particles as it falls from the top to the base of the melting layer. Given a mean population fall speed of $1 \mathrm{~m} \mathrm{~s}^{-1}$, a melting layer thickness of $400 \mathrm{~m}$, and a horizontal wind speed of $10 \mathrm{~m} \mathrm{~s}^{-1}$, particles at the base of the melting layer are displaced several kilometers away from the particles on top. First, there is no reason to expect that these horizontal inhomogeneity effects would lead to a substantial bias in the $Z-S$ relationship when the average is taken over the large number of samples available in the satellite datasets. Rather, horizontal displacement of the two populations would lead to noise, on average, rather than a bias. Nonetheless, to address this question, we used the OLYMPEX dataset. The horizontal gradient of $Z_{e}$ as measured from APR3 was examined for periods when the Citation flew horizontal legs in the region with temperatures from $-1^{\circ}$ to $-6^{\circ} \mathrm{C}$. It was found that there were brief periods during flights $4,10,11,20$, and 21 when there was considerable variability in $Z_{e}$; otherwise, the horizontal displacement issue would not have been a problem. From this discussion, we conclude that by using retrieved snowfall rates and rainfall rates at the top and base of the melting layer from the CloudSat, GPM, and TRMM products, the consistency between rain and snow retrievals are useful in identifying large errors in the retrievals.

To infer whether convection might be responsible for the relatively low values of the ratio of $S$ to $R$, the GPM data were evaluated without inclusion of data where the Ku-band reflectivity was above $40 \mathrm{~dB} Z$, thereby reducing the likelihood that strong updrafts were included in the calculations. This represented only $1.2 \%$ of the data points. The inclusion of these data points made virtually no difference in the trends observed in Fig. 10. Therefore, Fig. 10 suggests that there is general consistency in the retrievals. The change in the ratio $S / R$ as a function of $R$ for CloudSat is larger than that for GPM and TRMM. This is partly a result of the much larger range of rain rates covered by the CloudSat retrieval. For retrieved rain rates above about $0.4 \mathrm{~mm} \mathrm{~h}^{-1}$, the $S / R$ ratio varies from near 1.0 to about 0.2 for CloudSat, while that for GPM is near 0.3 and for TRMM, 0.5.

Figure 10 might suggest that the relatively steep dropoff in the ratio above about $1 \mathrm{~mm} \mathrm{~h}^{-1}$ may be due to systematic errors related to the snow- or rain-rate retrievals or a combination of both. We believe that for precipitation rates above a few millimeters per hour, the ratio of snow rate to rain rate from the top to the bottom of the melting layer should decline from 1.0, on average, by only relatively small amount because of the restricted opportunity for particle growth in the melting layer. The finding in Fig. 10 that the ratio derived the satellite retrievals drops by a factor of about $2-3$ for rain rates from about 1 to $10 \mathrm{~mm} \mathrm{~h}^{-1}$ implies that either the snow-rate retrievals are too low or the rain-rate retrievals are too high, or a combination of both. Given that the rain-rate retrievals are likely to be more accurate than the snowrate retrievals because of the complex nature of snow, it is likely that the snow-rate retrievals are too low. For rain rates below $1 \mathrm{~mm} \mathrm{~h}^{-1}$, it is also possible that the snow-rate retrievals are too large, although it is difficult to assess whether or not this is the case.

The relationship found between the radar reflectivity above the melting layer and the rain rate at the bottom 


\section{Comparison of Z-S Relationships, OLYMPEX vs All Domains $-10<\mathrm{T}<0^{\circ} \mathrm{C}$}
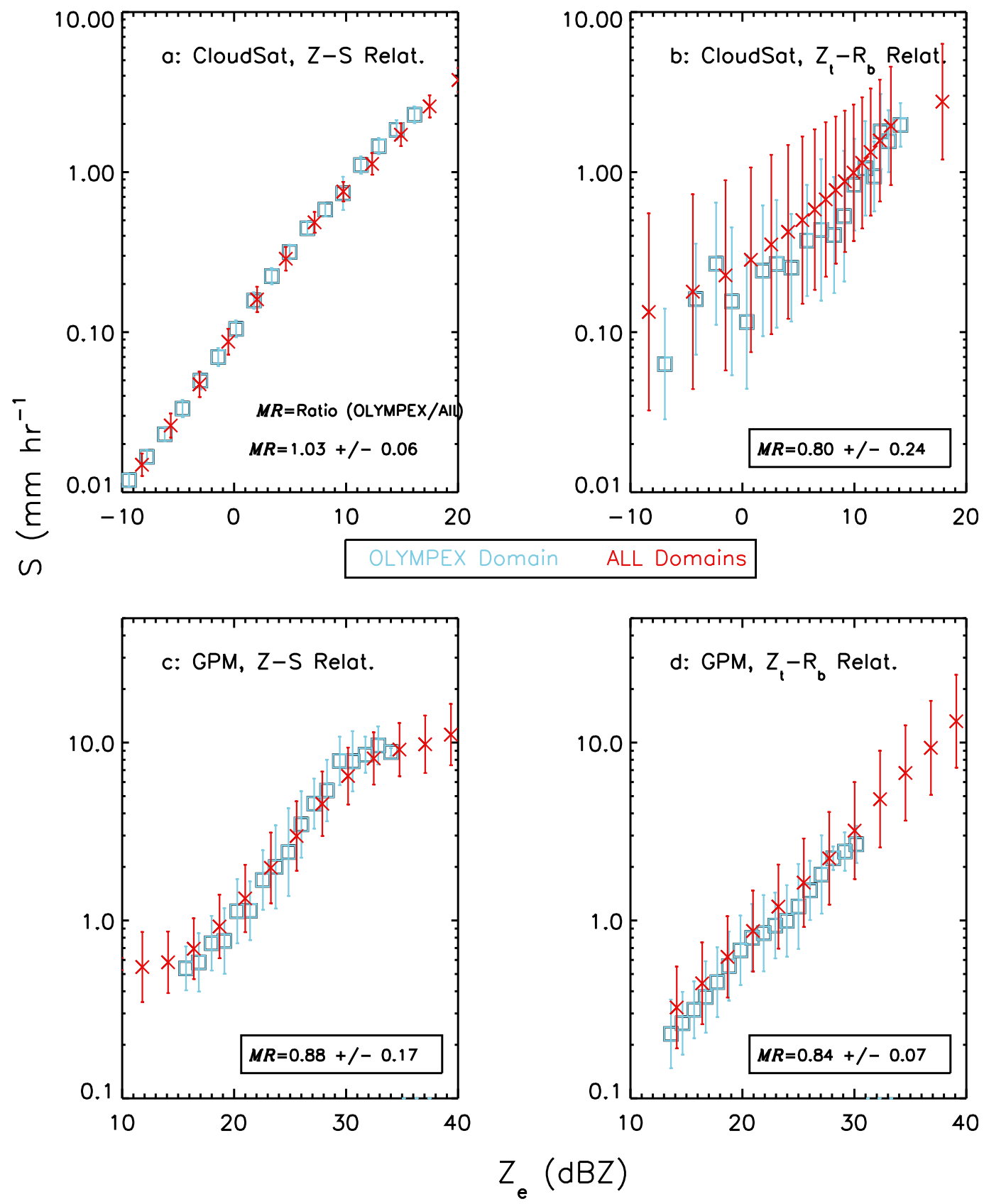

FIG. 14. Snowfall rate as a function of radar reflectivity from the global dataset and in the OLYMPEX domain. For the (a),(b) CloudSat data and (c),(d) GPM data, median values of $S$ are derived in 1-dBZ intervals, with error bars shown. In (a) and (c), the results from the satellite-based retrievals are shown, and in (b) and (d), for the MF method. The median ratio (MR) of the data from the OLYMPEX domain to the global dataset is shown.

of the melting layer $-Z_{t}$ versus $R$ from the $\mathrm{MF}$ method-is developed from the satellite-based datasets in Fig. 11. The reflectivities are limited to $40 \mathrm{~dB} Z$ because anything larger suggests a convective region where the assumption of mass conservation is not reliable owing to the likelihood that particles are growing and being carried upward in updrafts. Also, the CloudSat reflectivities are only for the regions identified as 
TABLE 1. Comparison of OLYMPEX data to satellite-borne radar retrievals.

\begin{tabular}{lcc}
\hline \hline & $\begin{array}{c}\text { Mean ratio } \\
\text { (retrieval/OLYMPEX) }\end{array}$ & $\begin{array}{c}\text { Median ratio } \\
\text { (retrieval/OLYMPEX) }\end{array}$ \\
Rain & Collocations \\
TRMM (Ku) & $0.24 \pm 0.11$ & 0.20 \\
GPM (Ku) & $0.37 \pm 0.17$ & 0.32 \\
GPM (Ka) & $0.71 \pm 0.32$ & 0.62 \\
CloudSat $(\mathrm{W})$ & $0.15 \pm 0.09$ & 0.16 \\
Snow & & \\
TRMM (Ku) & $0.13 \pm 0.05$ & 0.12 \\
GPM (Ku) & $0.29 \pm 0.10$ & 0.27 \\
GPM (Ka) & $0.71 \pm 0.32$ & 0.62 \\
CloudSat $(\mathrm{W})$ & $0.23 \pm 0.07$ & 0.24 \\
& Mass flux & \\
Snow & & 0.37 \\
TRMM (Ku) & $0.41 \pm 0.13$ & 0.72 \\
GPM (Ku) & $0.91 \pm 0.47$ & 1.11 \\
GPM (Ka) & $1.18 \pm 0.73$ & 0.32 \\
CloudSat $(\mathrm{W})$ & $0.30 \pm 0.07$ &
\end{tabular}

stratiform. For comparison, $Z_{e}$ measured by the APR-3 radar on board the NASA DC- 8 aircraft, and calculated $S$ derived from the Citation aircraft during collocation periods for GCPEX and OLYMPEX where the temperatures are limited to the range from $0^{\circ}$ to $-8^{\circ} \mathrm{C}$, are also plotted. For the shorter wavelengths $-\mathrm{W}$ and $\mathrm{Ka}$ bands-the CloudSat rain rates are somewhat lower than that for the collocation data for $Z_{t}<5 \mathrm{~dB} Z$ and consistent with it for $Z_{t}>5 \mathrm{~dB} Z$ (Fig. 11a). The slope of the data noted for GPM Ka band is considerably steeper than for the in situ data, although there are relatively few in situ collocations where $Z_{t}>20 \mathrm{~dB} Z$ (Fig. 11a). For the longer wavelengths, the retrievals and in situ data line up quite nicely, although there is relatively little overlap in the reflectivities between the collocation and retrieved datasets (Fig. 11b). The GPM Ku band and TRMM datasets line up quite closely. For that reason, it was decided to combine the two datasets by simply combining the individual data points for $R$ together and those for $Z_{t}$ together and finding the median values of $R$ in 100 intervals of $Z_{t}$. This combined dataset is obviously skewed to the longer-term TRMM dataset.

Note that for a given $Z_{e}$, the values of $R$ for GPM Ka band (Fig. 11a) are considerably higher than for Ku band (Fig. 11b), and the slope of the data points is considerably steeper, even where non-Rayleigh effects at Ka band are not likely to be significant $\left(Z_{e}<25 \mathrm{~dB}\right)$. A plot of $Z_{e}$ from GPM Ka- versus Ku-band data (not shown) suggests that there is considerably more noise in the Ka-band data and that this noise could lead to artificial enhancements in the retrieved rainfall rates. For this reason, in what follows we will not use the GPM Ka-band data to develop the $Z_{\mathrm{e}}-S$ relationships from the MF method.

Where CloudSat reflectivities overlap those from GPM-TRMM, the CloudSat rain rates (MF method) are about a twice those from the combined GPM-TRMM data. Error bars are not shown in the figure to reduce clutter. Using the results for the MF method, and by considering that the GPM Ku band and TRMM data can be combined because the results for both are quite similar, curves are developed for the CloudSat data, and the combined GPM-TRMM data. Given that W-band reflectivities appear to have relatively small non-Rayleigh scattering effects at reflectivities below about $10 \mathrm{dBZ}$ [Fig. 3a, and further analysis using TC4 W- and X-band radar data from the ER-2, from Heymsfield et al. (2016)], it is reasonable to combine the results for CloudSat $\left(Z_{e}<\right.$ $10 \mathrm{dBZ}$ ), GPM Ku band and TRMM to yield a composite relationship over a wide range of reflectivities (Fig. 12a). Also shown in Fig. 12a are the combined GCPEX data (Ka and $\mathrm{Ku}$ bands), and the combined OLYMPEX (W, $\mathrm{Ka}$, and $\mathrm{Ku}$ bands) data. The consistency between the OBS and MF data is reasonably good. Curves fitted to the datasets are shown.

The $S-Z_{e}$ relationships found from the CloudSat retrievals, combined GPM ( $S$ is the dual-wavelengthderived value, and $Z_{e}$ is from the Ku-band radar) and TRMM retrievals, the combined OLYMPEX, and combined GCPEX datasets are shown in Fig. 12b. Curve fits to those data are shown. A cursory comparison of Figs. 12a and $12 \mathrm{~b}$ suggests that the MF method produces higher values of $S$ than the retrievals but conforms better to the collocation data for a given value of $Z_{e}$.

To show more clearly the differences in the $S-Z_{e}$ relationships derived from the MF method and the retrievals, both sets of fitted relationships are plotted in Fig. 13a. It is noted that, in general, the former values are generally higher than the latter ones.

To quantify the differences in the $S-Z_{e}$ relationships derived from the MF method and the retrievals, first the median values of $S$ from the MF method and from the retrievals are derived in $1-\mathrm{dB} Z$ increments over the appropriate reflectivity ranges. Similarly, the median values of $S$ from the MF method are derived. Then, the ratios from the retrievals to the MF method are derived (Fig. 13b). The results indicate that, in the mean, the ratios for the GPM-TRMM combined data are quite good, $\sim 0.6$, whereas the mean ratio for CloudSat is considerably below 1.0 .

\section{Discussion}

The purpose of this section is to evaluate the CloudSat-GPM retrievals and earlier $S-Z_{e}$ relationships 
TABLE 2. Summary of snowfall-rate-reflectivity relationships. An em dash means not applicable for this wavelength.

\begin{tabular}{|c|c|c|c|c|}
\hline Reference & $\begin{array}{l}\text { Panel identifier in } \\
\text { Figs. } 15 \text { and } 16\end{array}$ & W band & Ka band & $\mathrm{Ku}$ band \\
\hline \multicolumn{5}{|l|}{ Based on Hiley et al. (2011) } \\
\hline Liu (2004) & a: LR & $c=0.16, p=0.71$ & $c=0.12, p=0.66$ & $c=0.10, p=0.51$ \\
\hline Liu (2008b) & $\mathrm{b}: \mathrm{L}$ & $c=0.80, p=0.36$ & - & - \\
\hline Hong (2007) & c: HA & $c=0.070, p=0.66$ & $c=0.045, p=0.54$ & $c=0.076, p=0.51$ \\
\hline Surussavadee and Staelin (2006) & $\mathrm{d}: \mathrm{SS}$ & $c=0.52, p=0.83$ & $c=0.18, p=1.36$ & $c=0.51, p=0.29$ \\
\hline M07 & e: M & $c=0.056, p=1.25$ & $c=0.83, p=0.09$ & - \\
\hline Noh et al. (2006) & $\mathrm{f}: \mathrm{N}$ & - & $c=0.96, p=0.04$ & $c=0.93, p=0.02$ \\
\hline \multicolumn{5}{|l|}{$S-c Z_{e}^{p}$ relationships ${ }^{\mathrm{a}}$} \\
\hline Puhakka (1975) & g: $P$ & $c=0.032, p=0.50$ & $c=0.032, p=0.50$ & $c=0.032, p=0.50$ \\
\hline Fujiyoshi et al. (1990) & $\mathrm{h}: \mathrm{F}$ & $c=0.004, p=0.92$ & $c=0.004, p=0.92$ & $\mathrm{c}=0.004, p=0.92$ \\
\hline Boucher and Wieler (1985) & i: BW & $c=0.37, p=0.61$ & $c=0.37, p=0.61$ & $c=0.37, p=0.61$ \\
\hline Huang et al. (2015) & j: HU1 & $c=0.038, p=0.61$ & $c=0.038, p=0.61$ & $c=0.038, p=0.61$ \\
\hline Huang et al. (2015) & k: HU2 & $c=0.034, p=0.69$ & $c=0.034, p=0.69$ & $c=0.034, p=0.69$ \\
\hline Heymsfield et al. (2016; W) & 1: HU2 & $c=0.41, p=0.46$ & - & - \\
\hline Heymsfield et al. (2016; X band) & m: H-X & $c=0.37, p=0.57$ & $c=0.37, p=0.57$ & $c=0.37, p=0.57$ \\
\hline \multicolumn{5}{|l|}{ New relationships $S=c \exp (p \mathrm{~dB} Z)$} \\
\hline CloudSat ( $Z-S$ fit in Fig. $12 b)$ & $\mathrm{n}: \mathrm{CS}$ & $c=0.083, p=0.21$ & - & - \\
\hline GPM-TRMM $Z-S$ combined (Fig. 12b) & o: GT & - & $c=0.018, p=0.15$ & $c=0.018, p=0.15$ \\
\hline CloudSat $\left[Z_{t}-R_{b}\right.$ fit (MF) in Fig. 12a $]$ & $\mathrm{p}: \mathrm{CBB}$ & $c=0.27, p=0.12$ & & \\
\hline GPM-TRMM combined (MF) (Fig. 12a) & q: GTBB & - & $c=0.054, p=0.13$ & $c=0.054, p=0.13$ \\
\hline CloudSat-GPM-TRMM mass flux combined & r: CGTBB & $c=0.18, p=0.20$ & $c=0.16, p=0.15$ & $c=0.16, p=0.15$ \\
\hline
\end{tabular}

${ }^{a}$ These relationships are not specifically derived for $\mathrm{X}$ or $\mathrm{C}$ band. However, they are applicable to Ku band, and given the reflectivities measured for OLYMPEX and GCPEX, non-Rayleigh effects should be small, and thus the Ku-band relationship is probably valid for X and $\mathrm{C}$ band.

in the context of the field program data and the results developed here.

Heavy reliance is placed in this study on the OLYMPEX dataset because of the availability of triple wavelength radar data collocated with the in situ aircraft and because in situ observations are available for both the ice and rain regions. A natural question to ask is, How representative are the relationships developed based on that dataset to ice clouds globally? The CloudSat and GPM Ku-band datasets were used to address that question. A grid box that covered the domain from $42^{\circ}$ to $46^{\circ} \mathrm{N}$ latitude and from $-122^{\circ}$ to $-126^{\circ}$ longitude was considered to be most representative of the geographical domain encompassing the OLYMPEX observations. To infer whether the $S-Z_{e}$ relationship found from the collocated dataset is representative, the retrieved $S$ and measured $Z_{e}$ data from this domain were compared to those derived globally.

Similarly, inferences were drawn using the MF method, relating $R$ at the base of the melting layer to $Z_{e}$ at the top of the melting layer. Ratios of the snowfall (rainfall) rate in the OLYMPEX domain to those globally were derived in the following way. First, for each increment of $1 \mathrm{~dB}$, a median value of $S(R)$ was derived, for both the global and regional datasets (Fig. 14). Then, the mean ratio (MR) of the two was found for all measured $Z_{e}$ (listed in the figure). The MR values for the $S-Z_{e}$ data are very close to unity with very little scatter in the relationship for the CloudSat and very close to unity for the GPM datasets (Figs. 14a,c). For the MF method, the $S-Z_{e}$ trend noted within the domain and globally are similar for both the CloudSat and GPM datasets, but the values of $R$ for a given value of $Z_{e}$ are $10 \%-15 \%$ lower for the domainaveraged values (Figs. 14b,d).

From this analysis, it can be concluded that the $S-Z_{e}$ relationships developed from the OLYMPEX dataset (and for GCPEX as well) are probably applicable to global conditions, whereas the coefficient in the $S-Z_{e}$ relationships from the MF method are $\sim 10 \%-15 \%$ low when considered globally. For the latter, the absolute accuracy of the method will depend upon the accuracy of the retrieved rainfall rate. These conclusions about the global applicability of these results depend on the degree to which the satellite retrieval products accurately represent the global variability of snowfall and rainfall characteristics.

The most direct way to evaluate the satellite retrievals in the context of the OLYMPEX dataset is to apply the retrieval algorithms to the APR-3 data and to compare the retrieved snowfall rates to the in situ or observed groundbased values. As this is a large task and can be the subject of a separate study, a simpler method is used here. Using 
the CloudSat, GPM, and TRMM $S-Z_{e}$ relationships developed from the retrievals (as in Fig. 12b, but separately for GPM Ka and $\mathrm{Ku}$ bands and TRMM), the median value of $S$ can be found in 1-dBZ increments of $Z_{e}$ over the range of the measurements. The in situ dataset can be evaluated in a similar way. The ratios of the retrieved to in situ snowfall rates in each $1-\mathrm{dB} Z$ reflectivity bin are compared and the mean and median ratios of the retrieved to observed snowfall rates for overlapping reflectivities have been derived (Table 1). The retrieved snowfall rates are, in general, considerably lower than those observed. In another evaluation, the MF method was used to derive the rainfall rates (equal to the snowfall rates) in 1-dBZ increments from $Z_{e}$ at the top of the ML. The results are much closer to those from the observations (Table 1).

There are numerous relationships between the radar reflectivity and snowfall rate that cover one or several radar frequencies. The OLYMPEX and GCPEX datasets provide a rich source of data to evaluate them, at least for the conditions encountered at each location and with the assumption that our calculated snowfall rates are reasonably $( \pm 25 \%)$ accurate.

The relationships and their sources, as well as the results, are presented in Table 2. A number of them do not directly derive the $Z_{\mathrm{e}}-S$ relationships but derive from the articles by Kulie and Bennartz (2009) and Hiley et al. (2011), who develop the relationships based on particle models. For example, Kulie and Bennartz (2009) utilized three different ice particle models from Surussavadee and Staelin (2006), Hong (2007), and Liu (2008b), combined with the Field et al. (2007) ice PSD, to generate $Z_{e}-S$ relationships and to study the uncertainty in snowfall retrievals due exclusively to the assumed ice particle shape. Instead of selecting individual ice particle models, though, Hiley et al. (2011) define an average $Z_{e}-S$ relationship based on almost 20 nonspherical ice particle models.

The OLYMPEX and GCPEX collocation data are used, together with the relationships listed in Table 2, to evaluate how well each of the relationships estimates the in situ-derived snowfall-rate data as a function of $Z_{e}$ (Figs. 15 and 16). Although the panels in each figure are small, a determination can be made whether the slope of the $S-Z_{e}$ relationship is reasonable (i.e., a relatively constant ratio across all reflectivities, meaning that the coefficient could be scaled up or down to get the correct $S$, on average) or whether the slope is too low or too high. For the OLYMPEX dataset, the relationships shown in Figs. 15d,k,p,q,r and Figs. 16d,k,p,q,r appear to fit the data reasonably well. The GCPEX results are somewhat different, where Figs. 15a,d,k,q,r and Figs. 16a,d,k,q,r fit the data quite well. In general, the CloudSat-GPM-TRMM combined MF method is among the best in representing
TABLE 3. Summary of relationships developed in this study. For the OLYMPEX snow-rate-reflectivity relationships $P=1000 \mathrm{hPa}, Z$ is the equivalent radar reflectivity factor $\left(\mathrm{mm}^{6} \mathrm{~m}^{-3}\right)$, and $S$ is the snow rate $\left(\mathrm{mm} \mathrm{h}^{-1}\right)$; these are the same for the OLYMPEX composite relationships with the addition of IWC $\left(\mathrm{g} \mathrm{m}^{-3}\right)$. The MF technique uses the rain rate $R\left(\mathrm{~mm} \mathrm{~h}^{-1}\right)$ at the base of the ML and $Z_{e}$ at the top of the ML.

\begin{tabular}{|c|c|}
\hline \multicolumn{2}{|c|}{ OLYMPEX snow-rate-reflectivity relationships } \\
\hline $\mathrm{Ku}($ all) & $S=0.32 Z^{0.45}$ \\
\hline $\mathrm{Ku}$ (without LW) & $S=0.28 Z^{0.46}$ \\
\hline $\mathrm{Ka}($ all $)$ & $S=0.30 Z^{0.52}$ \\
\hline Ka (without LW) & $S=0.28 Z^{0.51}$ \\
\hline $\mathrm{W}($ all $)$ & $S=0.75 Z^{0.61}$ \\
\hline W (without LW) & $S=0.60 Z^{0.59}$ \\
\hline dWR (Ku-Ka) (all) & $S=1.81 e^{0.095 \mathrm{dWR}}$ \\
\hline dWR $(\mathrm{Ku}-\mathrm{Ka})$ (without LW) & $S=2.78 e^{0.094 \mathrm{dWR}}$ \\
\hline \multicolumn{2}{|c|}{$\begin{array}{l}\text { OLYMPEX composite relationships } \\
\text { (wavelengths } \mathrm{W}, \mathrm{Ka} \text {, and } \mathrm{Ku} \text { ) }\end{array}$} \\
\hline & $\mathrm{IWC}=0.300 e^{0.0342 \mathrm{~dB} Z}$ \\
\hline & $\mathrm{IWC}=0.297 Z^{0.151}$ \\
\hline & $S=1.033 e^{0.0521 \mathrm{dBZ}}$ \\
\hline & $S=1.008 Z^{0.233}$ \\
\hline \multicolumn{2}{|c|}{ MF technique (wavelengths $\mathrm{W}$ and $\mathrm{Ku}$ ) } \\
\hline CloudSat only & $R=0.27 e^{0.119 Z}$ \\
\hline GPM-TRMM & $R=0.054 e^{0.130 Z}$ \\
\hline CloudSat-GPM-TRM & $R=0.18 e^{0.100 Z}$ \\
\hline \multicolumn{2}{|c|}{$\begin{array}{c}\text { Snow-rate relationships from retrieval } \\
\text { (wavelengths } \mathrm{W} \text { and } \mathrm{Ku})\end{array}$} \\
\hline CloudSat only & $S=0.083 e^{0.211 Z}$ \\
\hline GPM Ku-TRMM & $S=0.016 e^{0.153 Z}$ \\
\hline
\end{tabular}

both the OLYMPEX and GCPEX datasets. The relationships developed specifically for the collocation data in Figs. 8a-c are not plotted in Figs. 15 and 16, because they are specific fits to those datasets.

There are caveats that should be mentioned about the use of the mass-flux method. First, the method strictly applies only to conditions at and just above the melting layer, a temperature of $\sim 0^{\circ} \mathrm{C}$. To examine how temperature affects the retrievals, the CloudSat product derived for temperatures from $0^{\circ}$ to $-60^{\circ} \mathrm{C}$ (Fig. 12a) was used to derive exponential fits as in Figs. 14 and 15. At $0 \mathrm{dBZ}$, the mean snowfall rate in the range from $-50^{\circ}$ to $-60^{\circ} \mathrm{C}$ was $12 \%$ lower than for the interval from $0^{\circ}$ to $-10^{\circ} \mathrm{C}$ and for $10 \mathrm{dBZ}$ was $35 \%$ lower. For the GPM product, the mean snowfall rate in the range from $-50^{\circ}$ to $-60^{\circ} \mathrm{C}$ is $18 \%$ lower than at the interval from $0^{\circ}$ to $-10^{\circ} \mathrm{C}$ at $20 \mathrm{dBZ}$ and $22 \%$ lower at $30 \mathrm{~dB} Z$.

\section{Summary and conclusions}

This study uses two methods to develop snowfall rateradar reflectivity relationships, with the relationships summarized in Table 3. One approach, which is specific to particular geographical areas, uses collocated W-, $\mathrm{Ka}-$, and Ku-band radar measurements with in situ observations during the NASA GPM-sponsored field 


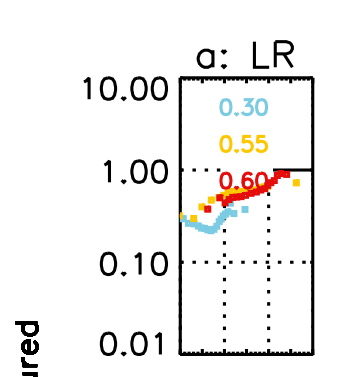



음

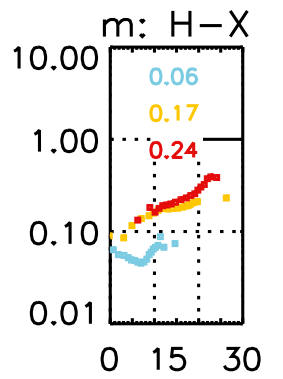

Rotio, Retrieved vs Meosured Snowrate, OLYMPEX
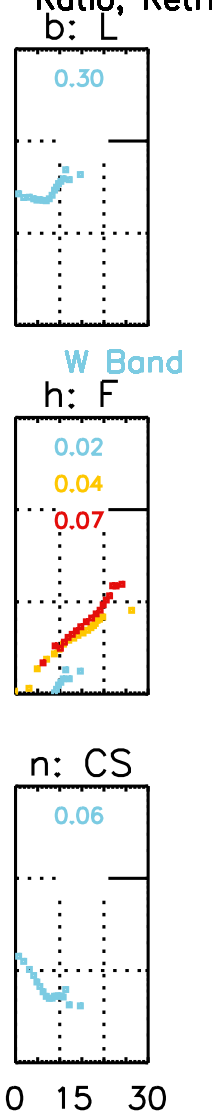
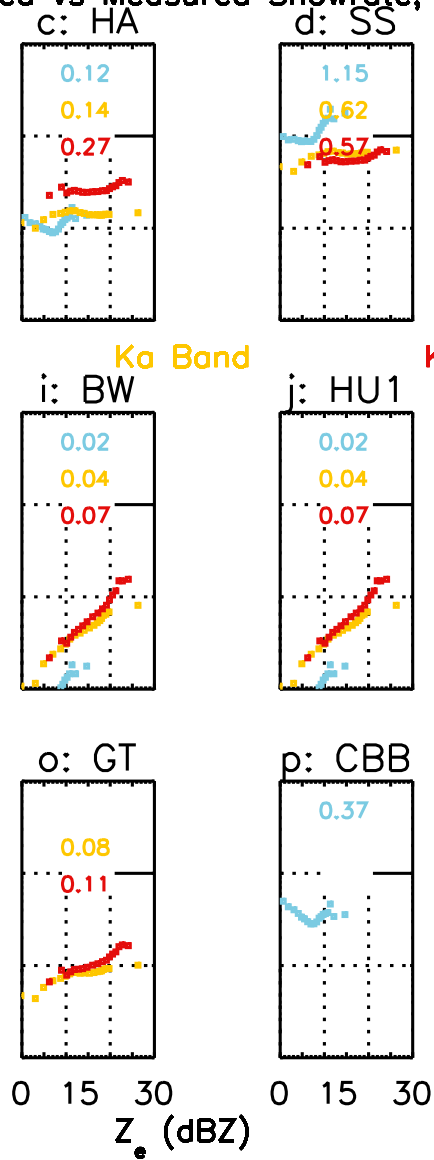
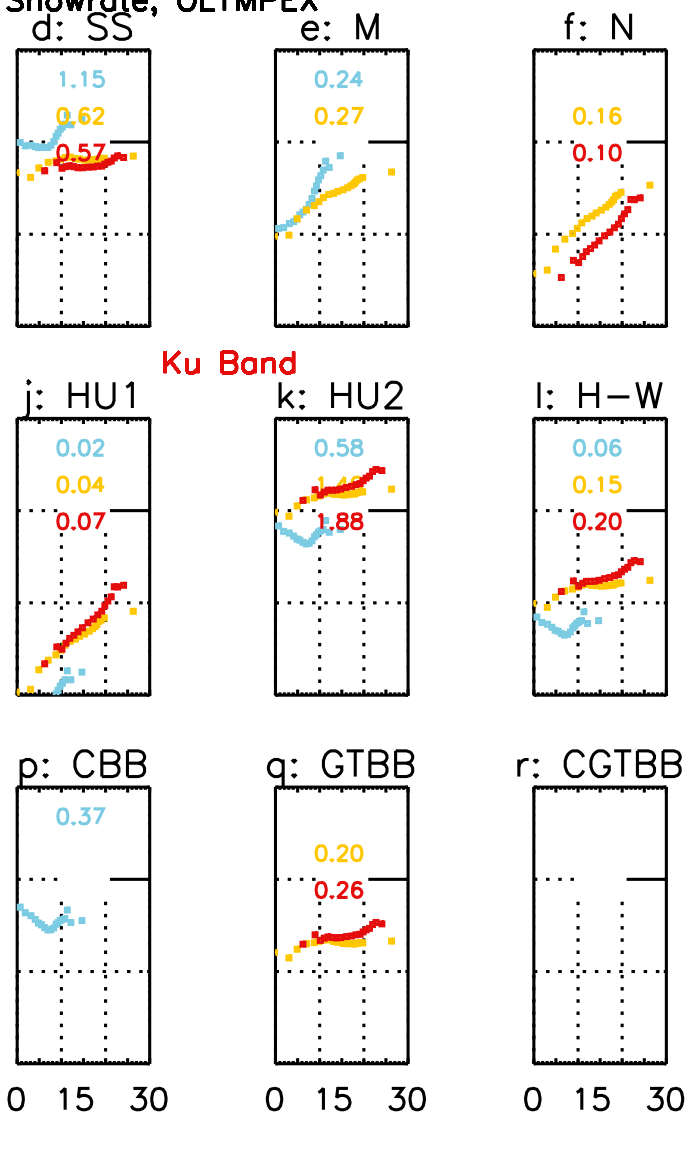

FIG. 15. Ratio of the snowfall rate from the retrieval algorithms shown in Table 2 to the corresponding reflectivity from the OLYMPEX dataset. The radar bands are identified with colors. The left and right abscissas are 0 and $30 \mathrm{~dB}$. The identification for each panel in the figure is shown in Table 2, columns 1-2, and the relationships for each radar band are shown in columns 3-5. Median ratios of the derived to in situ snowfall rates are shown in each panel.

programs GCPEX and OLYMPEX to directly develop $S-Z_{e}$ relationships. This method is an advance over earlier relationships in that it does not involve assumptions about the particle size distributions or the wavelength-dependent backscatter cross sections, nor does it involve long averaging times that are usually required from measurements of snowfall rate at the ground. Furthermore, as pointed out the text, the gradient in radar reflectivity through most of the ice cloud regions was relatively low; therefore, errors resulting from the large mismatch between the particle probe and radar sampling volumes should introduce relatively little error.

The second approach is intended to develop $S-Z_{e}$ relationships that are more generally applicable globally. Using data from two GPM-sponsored field programs together with modeling calculations, it is shown that the relative humidity through the melting layer (ML) of stratiform regions is such that the mass flux through the $\mathrm{ML}$ is sufficiently constant to consider that the rainfall rate at the base of the ML is nearly the same as the snowfall rate at the top of the ML. This result facilitates the development of relationships whereby the retrieved rainfall rate at the base of the ML, which can therefore be used as a proxy for the snowfall rate at the top of the ML, is related to $Z_{e}$. Because the retrieval of rainfall rate involves fewer assumptions than for snow, it is argued that these $S-Z_{e}$ relationships are more accurate than relationships that are developed specifically to retrieve $S$ from $Z_{e}$.

By applying different $S-Z_{e}$ relationships to the reflectivity data from the OLYMPEX and GCPEX collocations, it is shown that a composite W-, Ka-, and Ku-band relationship developed from the mass-flux method produces better agreement with the associated in situ-derived snowfall rates than the satellite-based snowfall-rate retrievals and most earlier relationships. The relationship is developed for a standard pressure level of $1000 \mathrm{hPa}$, and it can be adjusted to lower pressures (higher altitudes) using the pressure adjustment used for TRMM-GPM data, with 


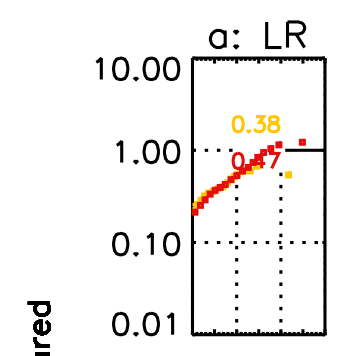

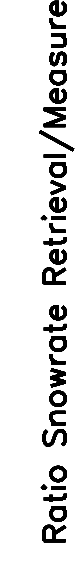
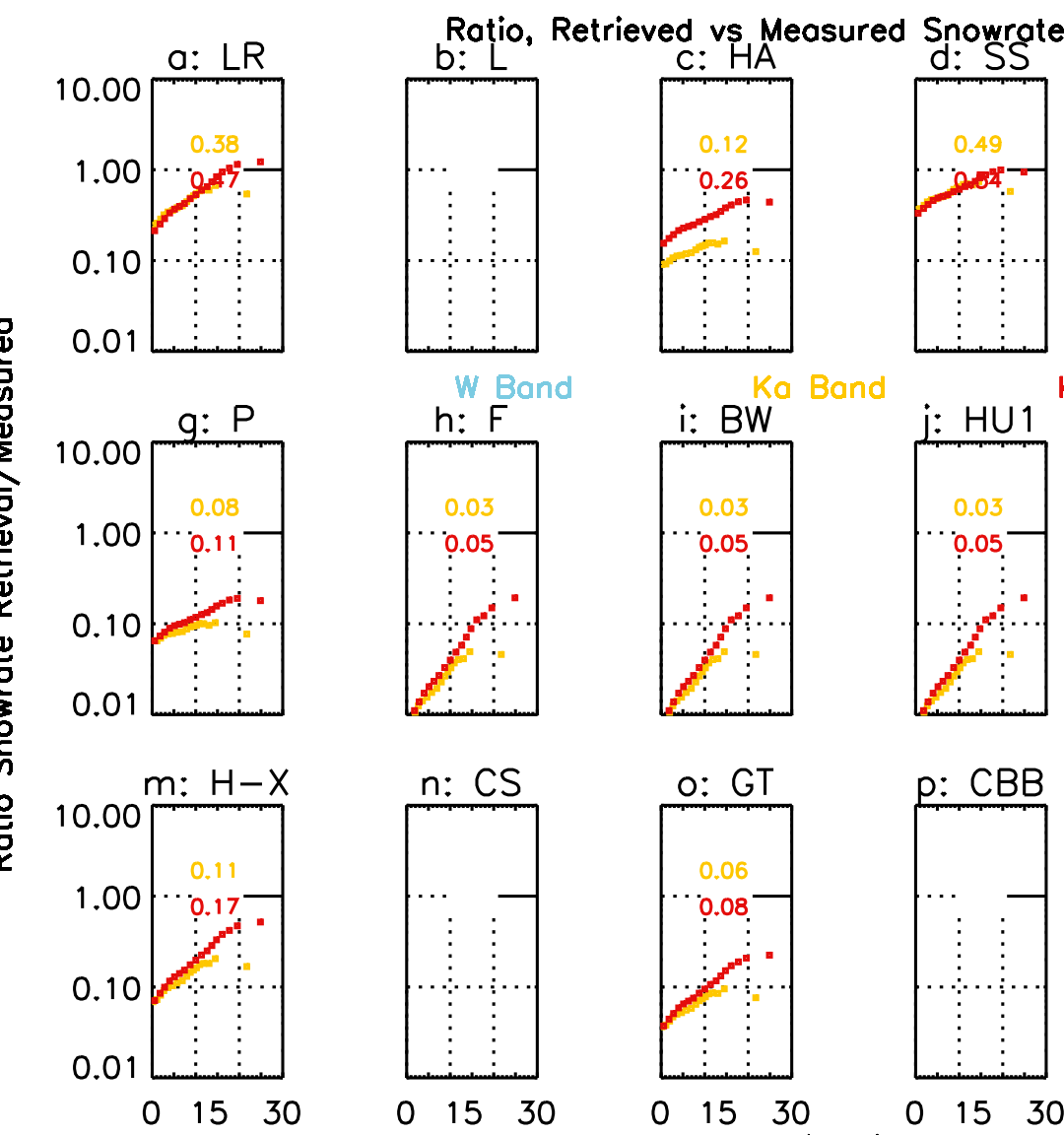

GCPEX
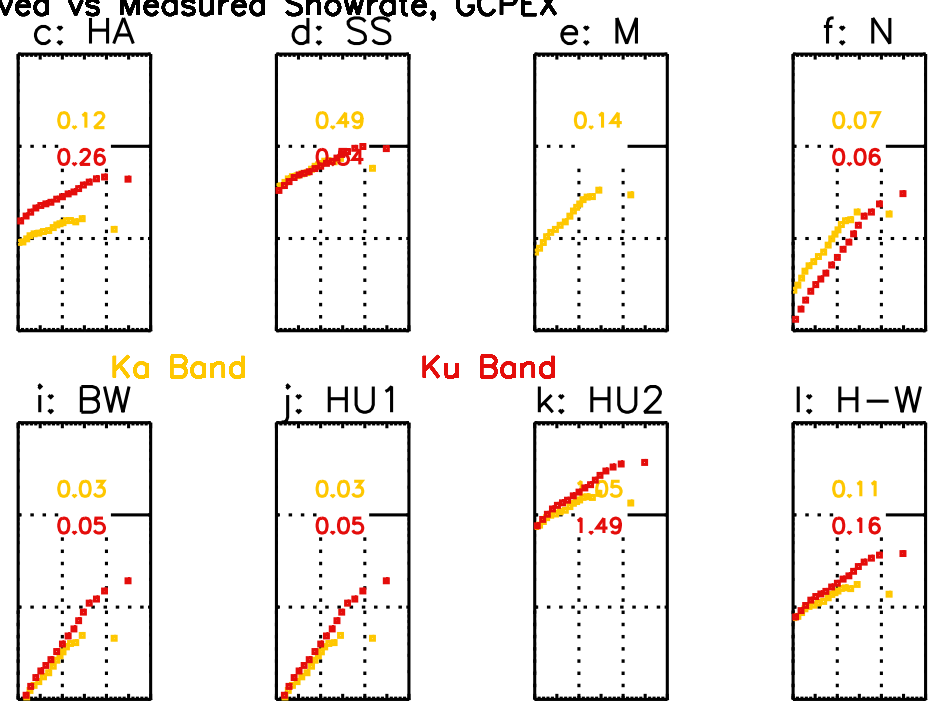

Ku Bond
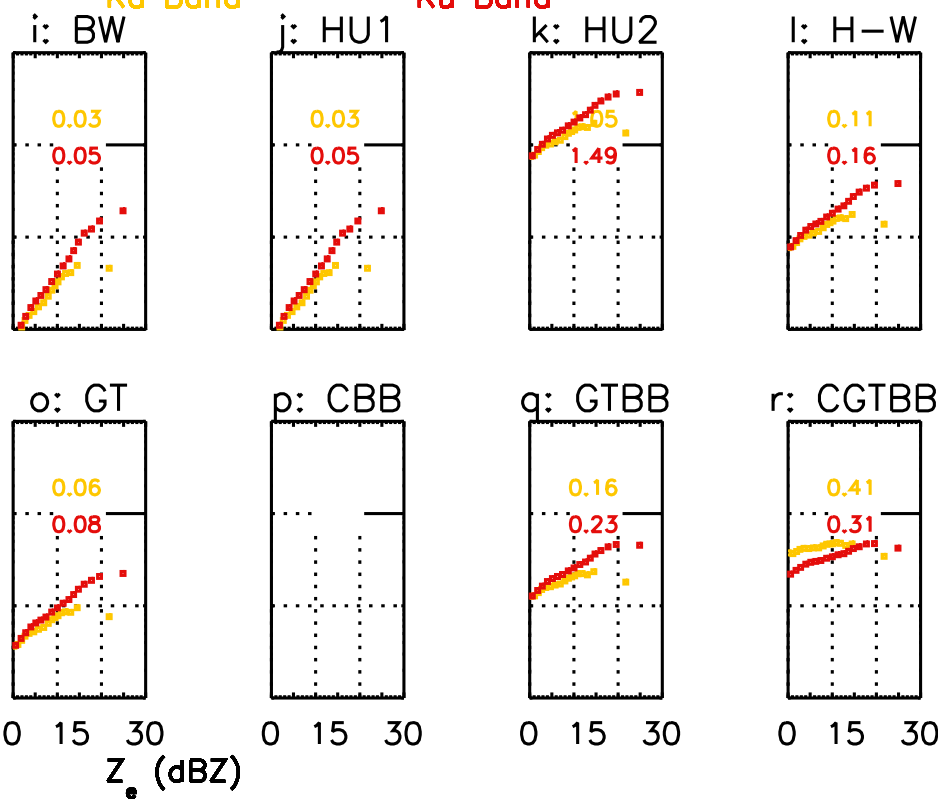

FIG. 16. As in Fig. 15, but for the GCPEX dataset. (Panels with no data are placeholders to facilitate more direct comparison with the results presented in Fig. 15.)

relatively little error. In addition to providing reasonable estimates of the snowfall rates, the method may be useful for improving the current retrieval algorithms.

The GCPEX and OLYMPEX datasets, and use of those from MC3E and IPHEx, provide a rich source of collocated radar and in situ data to further evaluate the current generation of satellite-based retrieval algorithms and the assumptions they use. Future studies, using the MC3E and IPHEx datasets, can also be used to evaluate the relationships developed here.

Acknowledgments. This research is supported by the National Science Foundation, CloudSat NASA Grant NNX16AP28G and PMM NNX13AH73G (AH, PI), by the Jet Propulsion Laboratory (JPL), sponsored by the National Aeronautics and Space Administration, Deb Vane, contract monitor. GL is supported by NASA NNX16AP27G. Portions of this work by NBW were performed at the University of Wisconsin-Madison for JPL. Operations of the Citation were supported by NASA grants GCPEX-NNX11AP12G, and
OLYMPEX-NNX15AL39G. CL was supported by PMM NNX16AD76G. The work performed by S. Tanelli and O. Sy was carried out at the Jet Propulsion Laboratory, California Institute of Technology under a contract with the National Aeronautics and Space Administration. Support from the ACE mission concept Science Working Group, Precipitation Measurement Missions program and NASA Weather Focus Area are gratefully acknowledged.

\section{REFERENCES}

AghaKouchak, A., A. Mehran, H. Norouzi, and A. Behrangi, 2012: Systematic and random error components in satellite precipitation data sets. Geophys. Res. Lett., 39, L09406, https:// doi.org/10.1029/2012GL051592.

Awaka, J., T. Iguchi, and K. Okamoto, 2009: TRMM PR standard algorithm 2A23 and its performance on bright band detection. J. Meteor. Soc. Japan, 87A, 31-52, https://doi.org/10.2151/ jmsj.87A.31.

Bennartz, R., and G. W. Petty, 2001: The sensitivity of microwave remote sensing observations of precipitation to ice particle size distributions. J. Appl. Meteor., 40, 345-364, https://doi.org/ 10.1175/1520-0450(2001)040<0345:TSOMRS>2.0.CO;2. 
Boucher, R. J., and J. G. Wieler, 1985: Radar determination of snowfall rate and accumulation. J. Climate Appl. Meteor., 24, 68-73, https://doi.org/10.1175/1520-0450(1985)024<0068: RDOSRA $>2.0 . \mathrm{CO} ; 2$.

Braun, S. A., and Coauthors, 2013: NASA's Genesis and Rapid Intensification Processes (GRIP) field experiment. Bull. Amer. Meteor. Soc., 94, 345-363, https://doi.org/10.1175/ BAMS-D-11-00232.1.

Fabry, F., and I. Zawadzki, 1995: Long-term radar observations of the melting layer of precipitation and their interpretation. J. Atmos. Sci., 52, 838-851, https://doi.org/10.1175/ 1520-0469(1995)052<0838:LTROOT>2.0.CO;2.

Field, P. R., A. J. Heymsfield, and A. Bansemer, 2006: Shattering and particle interarrival times measured by optical array probes in ice clouds. J. Atmos. Oceanic Technol., 23, 1357-1371, https://doi.org/10.1175/JTECH1922.1.

,-- , and -2007 : Snow size distribution parameterization for midlatitude and tropical ice clouds. J. Atmos. Sci., 64, 4346-4365, https://doi.org/10.1175/2007JAS2344.1.

Foote, G. B., and P. S. Du Toit, 1969: Terminal velocity of raindrops aloft. J. Appl. Meteor., 8, 249-253, https://doi.org/ 10.1175/1520-0450(1969)008<0249:TVORA > 2.0.CO;2.

Fujiyoshi, Y., T. Endoh, T. Yamada, K. Tsuboki, Y. Tachibana, and G. Wakahama, 1990: Determination of a $Z-R$ relationship for snowfall using a radar and high sensitivity snow gauges. J. Appl. Meteor., 29, 147-152, https://doi.org/10.1175/ 1520-0450(1990)029<0147:DOARFS $>2.0 . C O ; 2$.

Giangrande, S. E., T. Toto, A. Bansemer, M. R. Kumjian, S. Mishra, and A. V. Ryzhkov, 2016: Insights into riming and aggregation processes as revealed by aircraft, radar, and disdrometer observations for a 27 April 2011 widespread precipitation event. J. Geophys. Res. Atmos., 121, 5846-5863, https://doi.org/10.1002/2015JD024537.

Grecu, M., W. S. Olson, S. J. Munchak, S. Ringerud, L. Liao, Z. Haddad, B. L. Kelley, and S. F. McLaughlin, 2016: The GPM combined algorithm. J. Atmos. Oceanic Technol., 33, 2225-2245, https://doi.org/10.1175/JTECH-D-16-0019.1.

Haynes, J. M., T. S. L'Ecuyer, G. L. Stephens, S. D. Miller, C. Mitrescu, N. B. Wood, and S. Tanelli, 2009: Rainfall retrieval over the ocean with spaceborne W-band radar.J. Geophys. Res., 114, D00A22, https://doi.org/10.1029/2008JD009973.

Heymsfield, A. J., and C. D. Westbrook, 2010: Advances in the estimation of ice particle fall speeds using laboratory and field measurements. J. Atmos. Sci., 67, 2469-2482, https://doi.org/ 10.1175/2010JAS3379.1.

— C. Schmitt, and A. Bansemer, 2013: Ice cloud particle size distributions and pressure-dependent terminal velocities from in situ observations at temperatures from $0^{\circ}$ to $-86^{\circ} \mathrm{C}$. J. Atmos. Sci., 70, 4123-4154, https://doi.org/10.1175/JAS-D-12-0124.1.

, A. Bansemer, M. R. Poellot, and N. Wood, 2015: Observations of ice microphysics through the melting layer. J. Atmos. Sci., 72, 2902-2928, https://doi.org/10.1175/JAS-D-14-0363.1.

— S. Y. Matrosov, and N. B. Wood, 2016: Toward improving ice water content and snow-rate retrievals from radars. Part I: X and W bands, emphasizing CloudSat. J. Appl. Meteor. Climatol., 55, 2063-2090, https://doi.org/10.1175/JAMC-D-15-0290.1.

Hiley, M. J., M. S. Kulie, and R. Bennartz, 2011: Uncertainty analysis for CloudSat snowfall retrievals. J. Appl. Meteor. Climatol., 50, 399-418, https://doi.org/10.1175/2010JAMC2505.1.

Hitschfeld, W., and J. Bordan, 1954: Errors inherent in the radar measurement of rainfall at attenuating wavelengths. J. Meteor., 11, 58-67, https://doi.org/10.1175/1520-0469(1954)011<0058: EIITRM $>2.0 . \mathrm{CO} ; 2$.
Hong, G., 2007: Radar backscattering properties of nonspherical ice crystals at $94 \mathrm{GHz}$. J. Geophys. Res., 112, D22203, https:// doi.org/10.1029/2007JD008839.

Huang, G-J., V. N. Bringi, D. Moisseev, W. A. Petersen, L. Bliven, and D. Hudak, 2015: Use of 2D-video disdrometer to derive mean density-size and $\mathrm{Z}_{\mathrm{e}}-\mathrm{SR}$ relations: Four snow cases from the light precipitation validation experiment. Atmos. Res., 153, 34-48, https://doi.org/10.1016/j.atmosres.2014.07.013.

Iguchi, T., T. Kozu, R. Meneghini, J. Awaka, and K. Okamoto, 2000: Rain-profiling algorithm for the TRMM precipitation radar. J. Appl. Meteor., 39, 2038-2052, https://doi.org/10.1175/ 1520-0450(2001)040<2038:RPAFTT >2.0.CO;2.

- - - J. Kwiatkowski, R. Meneghini, J. Awaka, and K. Okamoto, 2009: Uncertainties in the rain profiling algorithm for the TRMM precipitation radar. J. Meteor. Soc. Japan, 87A, 1-30, https://doi.org/10.2151/jmsj.87A.1.

- S. Seto, R. Meneghini, N. Yoshida, J. Awaka, and T. Kubota, 2010: GPM/DPR level-2 algorithm theoretical basis document JAXA EORC/NASA PPS, 72 pp., https://pmm.nasa.gov/sites/ default/files/document_files/ATBD_GPM_DPR_n3_dec15.pdf.

Kozu, T., T. Iguchi, T. Shimomai, and N. Kashiwagi, 2009: Raindrop size distribution modeling from a statistical rain parameter relation and its application to the TRMM precipitation radar rain retrieval algorithm. J. Appl. Meteor. Climatol., 48, 716-724, https://doi.org/10.1175/ 2008JAMC1998.1.

Kulie, M. S., and R. Bennartz, 2009: Utilizing spaceborne radars to retrieve dry snowfall. J. Appl. Meteor. Climatol., 48, 2564-2580, https://doi.org/10.1175/2009JAMC2193.1.

, T. J. Greenwald, Y. Chen, and F. Weng, 2010: Uncertainties in microwave properties of frozen precipitation: Implications for remote sensing and data assimilation. J. Atmos. Sci., 67, 3471-3487, https://doi.org/10.1175/2010JAS3520.1.

Kuo, K.-S., and Coauthors, 2016: The microwave radiative properties of falling snow derived from nonspherical ice particle models. Part I: An extensive database of simulated pristine crystals and aggregate particles, and their scattering properties. J. Appl. Meteor. Climatol., 55, 691-708, https://doi.org/ 10.1175/JAMC-D-15-0130.1.

Lawson, R. P., D. O'Connor, P. Zmarzly, K. Weaver, B. Baker, Q. Mo, and H. Jonsson, 2006: The 2D-S (stereo) probe: Design and preliminary tests of a new airborne, high-speed, highresolution particle imaging probe. J. Atmos. Oceanic Technol., 23, 1462-1477, https://doi.org/10.1175/JTECH1927.1.

Lebsock, M. D., and T. S. L'Ecuyer, 2011: The retrieval of warm rain from CloudSat. J. Geophys. Res., 116, D20209, https://doi.org/10.1029/2011JD016076.

,,-- D. Vane, G. Stephens, and D. Reinke, 2011: Level 2C RAIN-PROFILE product process description and interface control document, algorithm version 0.0. JPL Rep., 14 pp., http:// www.cloudsat.cira.colostate.edu/sites/default/files/products/files/ 2C-RAIN-PROFILE-PDICD.P_R04.20110620.pdf.

L'Ecuyer, T. S., and G. L. Stephens, 2002: An estimation-based precipitation retrieval algorithm for attenuating radars. J. Appl. Meteor., 41, 272-285, https://doi.org/10.1175/ 1520-0450(2002)041<0272:AEBPRA > 2.0.CO;2.

Liu, G., 2004: Approximation of single scattering properties of ice and snow particles for high microwave frequencies. J. Atmos. Sci., 61, 2441-2456, https://doi.org/10.1175/ 1520-0469(2004)061<2441:AOSSPO > 2.0.CO;2. , 2008a: A database of microwave single-scattering properties for nonspherical ice particles. Bull. Amer. Meteor. Soc., 89, 1563-1570, https://doi.org/10.1175/2008BAMS2486.1. 
- 2008b: Deriving snow cloud characteristics from CloudSat observations. J. Geophys. Res., 113, D00A09, https://doi.org/ 10.1029/2007JD009766.

Marshall, J. S., and W. M. K. Palmer, 1948: The distribution of raindrops with size. J. Meteor., 5, 165-166, https://doi.org/ 10.1175/1520-0469(1948)005<0165:TDORWS > 2.0.CO;2.

Matrosov, S. Y., 2007: Modeling backscatter properties of snowfall at millimeter wavelengths. J. Atmos. Sci., 64, 1727-1736, https://doi.org/10.1175/JAS3904.1.

— C. Campbell, D. Kingsmill, and E. Sukovich, 2009: Assessing snowfall rates from $\mathrm{X}$-band radar reflectivity measurements. J. Atmos. Oceanic Technol., 26, 2324-2339, https://doi.org/ 10.1175/2009JTECHA1238.1.

McFarquhar, G. M., M. S. Timlin, R. M. Rauber, B. F. Jewett, J. A. Grim, and D. P. Jorgensen, 2007: Vertical variability of cloud hydrometeors in the stratiform region of mesoscale convective systems and bow echoes. Mon. Wea. Rev., 135, 3405-3428, https://doi.org/10.1175/MWR3444.1; Corrigendum, 137, 1493, https://doi.org/10.1175/2009MWR2938.1.

Mitchell, D. L., and A. J. Heymsfield, 2005: Refinements in the treatment of ice particle terminal velocities, highlighting aggregates. J. Atmos. Sci., 62, 1637-1644, https://doi.org/10.1175/ JAS3413.1.

Neumann, A., 2016: Investigating evaporation of melting ice particles within a bin melting layer model. Ph.D. dissertation, University of North Dakota, $98 \mathrm{pp}$.

Noh, Y.-J., G. Liu, E.-K. Seo, J. R. Wang, and K. Aonashi, 2006: Development of a snowfall retrieval algorithm at high microwave frequencies. J. Geophys. Res., 111, D22216, https:// doi.org/10.1029/2005JD006826.

Puhakka, T., 1975: On the dependence of the Z-R relation on the temperature in snowfall. Preprints, 16th Radar Meteorology Conf., Houston, TX, Amer. Meteor. Soc., 504-507.

Sadowy, G. A., A. C. Berkun, W. Chun, E. Im, and S. L. Durden, 2003: Development of an advanced airborne precipitation radar. Microwave J., 46, 84-98.

Sekhon, R. S., and R. C. Srivastava, 1970: Snow size spectra and radar reflectivity. J. Atmos. Sci., 27, 299-307, https://doi.org/ 10.1175/1520-0469(1970)027<0299:SSSARR > 2.0.CO;2.
Skofronick-Jackson, G., and Coauthors, 2015: Global Precipitation Measurement Cold Season Precipitation Experiment (GCPEX): For measurement's sake, let it snow. Bull. Amer. Meteor. Soc., 96, 1719-1741, https://doi.org/10.1175/BAMS-D-13-00262.1.

Stephens, G. L., and Coauthors, 2002: The CloudSat mission and the A-Train: A new dimension of space-based observations of clouds and precipitation. Bull. Amer. Meteor. Soc., 83, 17711790, https://doi.org/10.1175/BAMS-83-12-1771.

Surussavadee, C., and D. H. Staelin, 2006: Comparison of AMSU millimeter-wave satellite observations, MM5/TBSCAT predicted radiances, and electromagnetic models for hydrometeors. IEEE Trans. Geosci. Remote Sens., 44, 2667-2678, https://doi.org/10.1109/TGRS.2006.873275.

Szyrmer, W., and I. Zawadzki, 1999: Modeling of the melting layer. Part I: Dynamics and microphysics. J. Atmos. Sci., 56, 3573-3592, https://doi.org/10.1175/1520-0469(1999)056<3573: MOTMLP $>2.0 . \mathrm{CO} ; 2$.

Trenberth, K. E., and Coauthors, 2007: Observations: Surface and atmospheric climate change. Climate Change 2007: The Physical Science Basis, S. Solomon et al., Eds., Cambridge University Press, 235-336.

TRMM Precipitation Radar Team, 2011: Tropical Rainfall Measuring Mission (TRMMM) Precipitation Radar algorithm: Instruction manual for version 7. JAXA/NASA, $170 \mathrm{pp}$., http:// www.eorc.jaxa.jp/TRMM/documents/PR_algorithm_product_ information/pr_manual/PR_Instruction_Manual_V7_L1.pdf.

Wolfe, J. P., and J. R. Snider, 2012: A relationship between reflectivity and snow rate for a high-altitude S-band radar. J. Appl. Meteor. Climatol., 51, 1111-1128, https://doi.org/ 10.1175/JAMC-D-11-0112.1.

Wood, N. B., T. S. L'Ecuyer, D. Vane, G. Stephens, and P. Partain, 2013: Level 2C snow profile process description and interface control document, algorithm version P_R04. JPL Doc., 21 pp., http://www.cloudsat.cira.colostate.edu/sites/default/files/products/ files/2C-SNOW-PROFILE_PDICD.P_R04.20130210.pdf.

, - - A. J. Heymsfield, and G. L. Stephens, 2015: Microphysical constraints on millimeter-wavelength scattering properties of snow particles. J. Appl. Meteor. Climatol., 54, 909-931, https://doi.org/10.1175/JAMC-D-14-0137.1. 